UNIVERSIDADE DE SÃO PAULO

FACULDADE DE ECONOMIA, ADMINISTRAÇÃO E CONTABILIDADE DEPARTAMENTO DE ECONOMIA PROGRAMA DE PÓS-GRADUAÇÃO EM ECONOMIA

IMPACTO REGIONAL DA POLÍTICA MONETÁRIA NO BRASIL: UMA ABORDAGEM BAYESIANA

Fábio Martins Serrano

Orientador: Prof. Dr. Márcio Issao Nakane

SÃO PAULO

2014 
Prof. Dr. Marco Antonio Zago

Reitor da Universidade de São Paulo

Prof. Dr. Adalberto Américo Fischmann

Diretor da Faculdade de Economia, Administração e Contabilidade

Prof. Dr. Hélio Nogueira da Cruz

Chefe do Departamento de Economia

Prof. Dr. Márcio Issao Nakane

Coordenador do Programa de Pós-Graduação em Economia

FÁBIO MARTINS SERRANO 


\section{IMPACTO REGIONAL DA POLÍTICA MONETÁRIA NO BRASIL: UMA ABORDAGEM BAYESIANA}

Dissertação apresentada ao

Departamento de Economia da

Faculdade de Economia, Administração

e Contabilidade da Universidade de São

Paulo como requisito para a obtenção do título de Mestre em Ciências.

Orientador: Prof. Dr. Márcio Issao Nakane

Versão Corrigida

(versão original disponível na Faculdade de Economia, Administração e Contabilidade)

\section{SÃO PAULO}

2014 
FICHA CATALOGRÁFICA

Elaborada pela Seção de Processamento Técnico do SBD/FEA/USP

\section{Serrano, Fábio Martins}

Impacto regional da politica monetária no Brasil: uma abordagem bayesiana / Fábio Martins Serrano. -- São Paulo, 2014 $80 \mathrm{p}$.

Dissertação (Mestrado) - Universidade de São Paulo, 2014. Orientador: Márcio Issao Nakane.

1. Política monetária - Brasil 2. Economia regional 3. Econometria bayesiana I. Universidade de São Paulo. Faculdade de Economia, Administração e Contabilidade. II. Título.

CDD - 332.460981 
Aos meus pais. 


\section{AGRADECIMENTOS}

Em primeiro lugar, agradeço aos meus pais, Maria Thereza e Joaquin, pelo apoio e incentivo aos meus estudos.

Ao meu orientador, Márcio Nakane, por toda a paciência e ajuda ao longo desse processo. Com poucas palavras, sempre soube transmitir o essencial, e sua contribuição para a conclusão deste trabalho foi inestimável.

Aos professores Carlos Eduardo Gonçalves e Pedro Garcia Duarte, pelos comentários feitos na mini-banca e na qualificação.

Aos professores Tao Zha, Marco Del Negro, Fabio Canova, Frank Schorfheide, Gary Koop, Dimitris Korobilis e Paulo Picchetti, por toda a ajuda prestada. Em especial, gostaria de agradecer os professores Ellis Tallman e Tatevik Sekhposyan pela paciência com que me ajudaram a solucionar diversas dúvidas e pelas palavras de incentivo.

Aos professores Mauro Rodrigues e Antônio Carlos Rosso, pelo exemplo de dedicação à docência.

À professora Vera Lúcia Fava, pelo trabalho incansável por um curso melhor. Sua dedicação, profissionalismo e caráter são inspiradores. Muito obrigado por todas as oportunidades que me proporcionou e pelo privilégio da amizade.

A todos os amigos que fizeram esses anos mais fáceis. Ao Leonardo Mello, pela companhia desde o tempo de graduação. Ao Pedro Funari, pelas monitorias e projetos que dividimos. À minha turma de mestrado no IPE-USP, especialmente ao Maurício, Dimas, Perez, Gabriel, Carnaúba, Rodrigo, Guilherme, Luiz, Ednaldo e Luísa, pelos cafés e bandejões. A todos da turma mais nova, em especial ao Dantas, Schneider, Neto, Artur, Rai, Danilo, Matheus e Michael, pela companhia quando me mudei para a sala de baixo. $E$ aos amigos de fora, especialmente a todos com quem compartilhei bons momentos no Osmar.

Por último, à Julia, cuja ajuda, apoio e companhia foram essenciais para a conclusão deste projeto. 


\section{RESUMO}

Esta dissertação tem como objetivo (i) estimar a resposta das Unidades Federativas brasileiras a um choque de política monetária e, caso as mesmas respondam de forma assimétrica, (ii) compreender os determinantes de tal heterogeneidade. Para tanto, faz-se uso de técnicas de econometria Bayesiana, assim como em Francis et al (2012). Tais técnicas visam contornar o problema de dimensionalidade inerente aos modelos que englobam um número elevado de variáveis, além de permitir modelar formalmente a incerteza existente na escolha do conjunto de covariadas adequado. A resposta das Unidades Federativas foi estimada através de um VAR Bayesiano. A evidência encontrada sugere que as Unidades Federativas brasileiras respondem de forma assimétrica às inovações de política monetária. As regiões Sul e Sudeste apresentam as maiores contrações em resposta ao choque, enquanto a região Norte não apresentou sensibilidade. Para o estudo dos determinantes das assimetrias regionais, utilizou-se o Bayesian Model Averaging. Apesar do grande grau de incerteza acerca dos determinantes da heterogeneidade encontrada, Estados com maior porcentagem de empregos provenientes da indústria de transformação tendem a ser mais sensíveis às variações exógenas de política monetária. O resultado encontrado aponta para a relevância do canal de juros na determinação das assimetrias no nível estadual. 


\begin{abstract}
The purpose of this dissertation is to $(i)$ estimate the impact of a monetary policy shock at the Brazilian state level economies and, if they do respond asymmetrically, (ii) to investigate the causes of this heterogeneity. Therefore, Bayesian econometric techniques were used, following Francis et al (2012). These techniques not only overcome the problem of dimensionality, inherent to large size models, but also provide a formal framework to model the uncertainties involving the choice of the appropriate set of covariates. A Bayesian VAR was estimated in order to access the regional responses. The results indicate that the Brazilian state level monetary policy innovation responses are asymmetric. The greatest responses were found at the South and Southeast Regions, while the North Region seems to be insensible to an interest rate shock. The Bayesian Model Averaging technique was implemented to access the determinants of the state level asymmetries. Despite the large degree of uncertainty about the determinants of the response heterogeneity, states with greater share of manufacturing jobs tend to be more sensible to exogenous changes in monetary policy. The results found points to the importance of the interest rate channel in determining Brazilian state level asymmetries.
\end{abstract}




\section{SUMÁRIO}

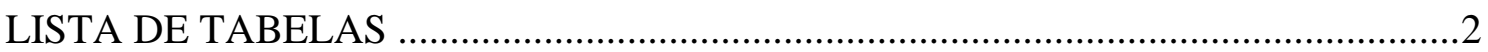

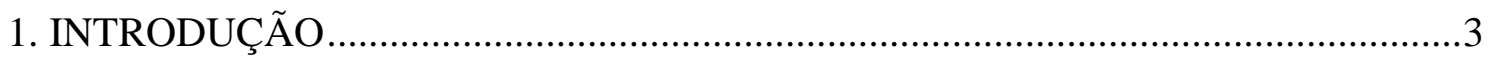

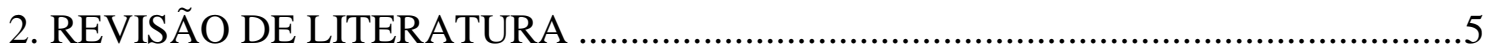

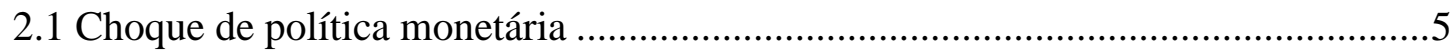

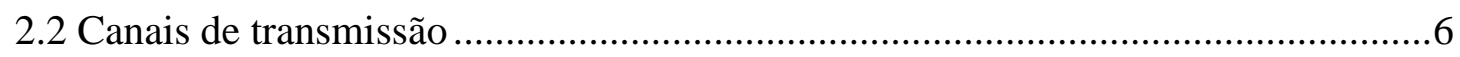

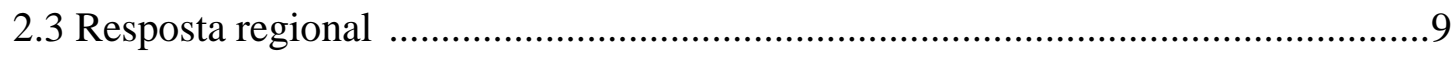

3. EFEITO REGIONAL DE POLÍTICA MONETÁRIA ….......................................... 19

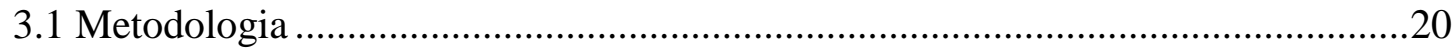

3.1.1 SVAR Bayesiano: O caso exatamente identificado .......................................20

3.1.2 SVAR Bayesiano: O caso sobre identificado ...........................................24

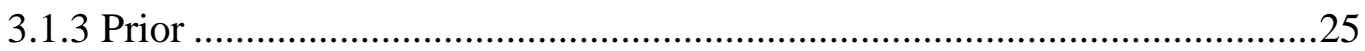

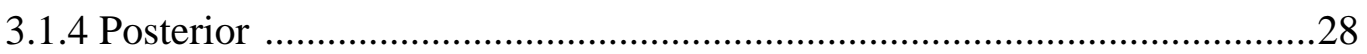

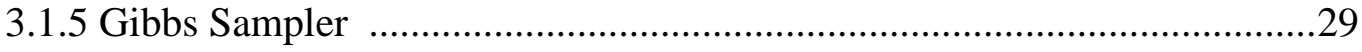

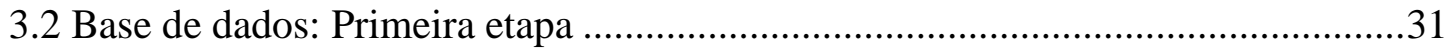

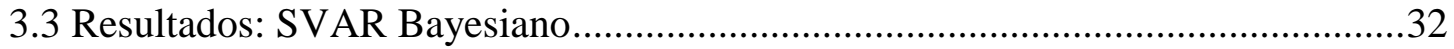

4. POR QUE OS ESTADOS RESPONDEM DE FORMA DIFERENTE A UM CHOQUE DE POLÍTICA MONETÁRIA? .............................................................49

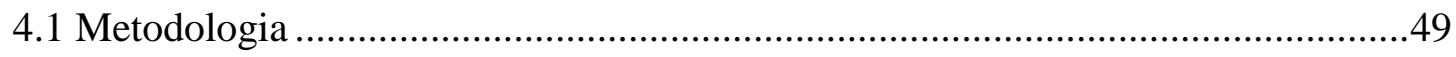

4.1.1 Bayesian Model Averaging .................................................................49

4.1.2 Markov Chain Monte Carlo Model Composition .....................................53

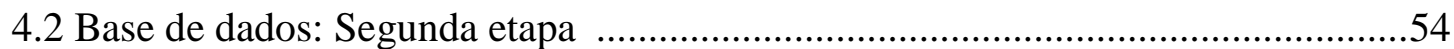

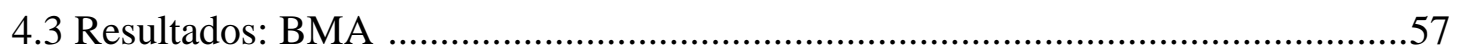

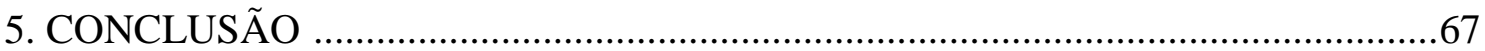

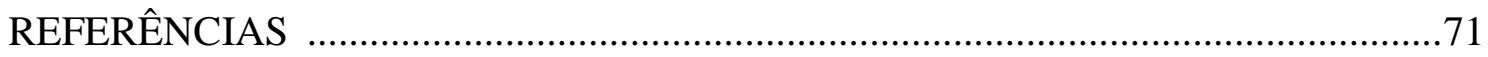




\section{LISTA DE TABELAS}

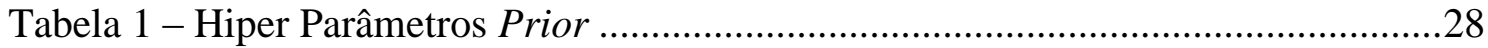

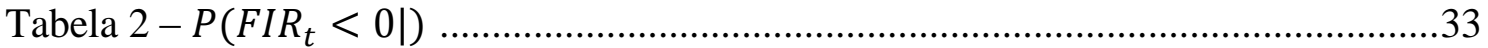

Tabela 3 - Resposta Acumulada Após 48 Meses ...............................................................41

Tabela 4 - Resposta Acumulada Após 48 Meses - 68\% I.C. ..........................................42

Tabela 5 - Resposta Acumulada Após 48 Meses - 90\% I.C. .........................................43

Tabela 6 - Resposta Acumulada Máxima ...................................................................4

Tabela 7 - Resposta Acumulada - Períodos Diferentes ...............................................46

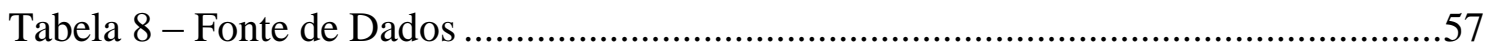

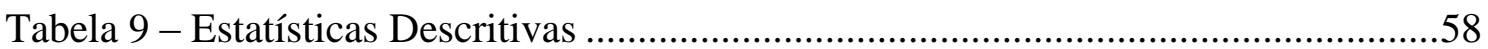

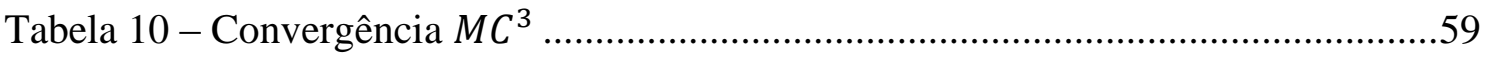

Tabela 11 - Importância dos Canais de Transmissão - Resposta Total..........................62

Tabela 12 - Importância dos Canais de Transmissão - Resposta Máxima....................63

Tabela 13 - Intervalo de Credibilidade Condicional à Inclusão - Resposta Total

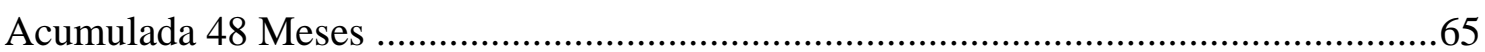

Tabela 14 - Intervalo de Credibilidade Condicional à Inclusão - Resposta Máxima

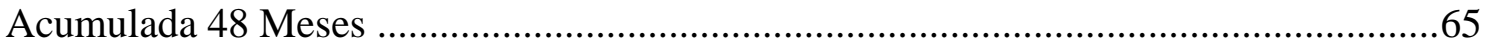

Tabela 15 - Probabilidade de Coeficiente Positivo - Condicional à Inclusão................66 


\section{INTRODUÇÃO}

A literatura sobre impacto regional de política monetária se debruça sobre duas questões principais. Primeiro, investiga se um choque de política monetária tem impactos assimétricos sobre o nível de atividade de desagregações subnacionais. Segundo, procura esclarecer quais os determinantes dessas assimetrias de resposta.

Apesar das duas questões serem profundamente ligadas, a literatura empírica nacional dedicou-se muito mais ao estudo da primeira agenda de pesquisa (VASCONCELOS; DA FONSECA, 2002; ARAÚJO, 2004; BERTANHA; HADDAD, 2008; ROCHA, 2007; ROCHA et al, 2011), deixando a compreensão dos determinantes da heterogeneidade de resposta ao choque de política monetária pouco desenvolvida. Apenas recentemente se avançou no sentido de investigar de forma mais rigorosa quais as causas das assimetrias existentes (ROCHA et al, 2011).

Este estudo visa não só compreender como as diferentes Unidades Federativas brasileiras respondem a uma inovação na política do Banco Central, mas também investigar quais as possíveis causas para essa heterogeneidade. Para tanto, seguiremos a estratégia empírica proposta no trabalho de Carlino e Defina (1999), que consiste em estimar as respostas regionais a um choque comum de política monetária através de um modelo VAR e regredir os resultados obtidos contra variáveis proxy para os canais de transmissão de política monetária.

Baseado em Francis et al (2012), utilizaremos métodos Bayesianos para enfrentar problemas inerentes às duas etapas dessa metodologia. Mais especificamente, o problema da dimensionalidade, comum em modelos VAR, será contornado com a utilização de um VAR Bayesiano, construído com a prior proposta em Sims e Zha (1998). Por fim, será utilizado o Bayesian Model Averaging para lidar com a incerteza acerca de quais covariadas são relevantes para a segunda etapa do estudo.

Dessa forma, pretende-se avançar na compreensão do comportamento das economias regionais brasileiras frente a um choque de política monetária, tratando a questão dentro de um arcabouço comum, como em Rocha et al 2011. Espera-se obter avanços ao aplicar metodologias econométricas Bayesianas, que permitem contornar problemas inerentes aos modelos utilizados. 
A evidência encontrada sugere que as Unidades Federativas brasileiras respondem de forma assimétrica às inovações de política monetária. As regiões Sul e Sudeste apresentam as maiores contrações em resposta ao choque, enquanto a região Norte não apresentou sensibilidade. Apesar do grande grau de incerteza acerca dos determinantes da heterogeneidade encontrada, Estados com maior porcentagem de empregos provenientes da indústria de transformação tendem a ser mais sensíveis às variações exógenas de política monetária. O resultado encontrado aponta para a relevância do canal de juros na determinação das assimetrias no nível estadual.

O restante do trabalho está organizado em três seções, além desta introdução e das conclusões finais. A próxima seção faz uma breve revisão da literatura, passando pela definição de um choque de política monetária, seus principais canais de transmissão, e as evidências empíricas de seus possíveis impactos regionais diferenciados. Em seguida, é abordada a questão da heterogeneidade regional. Esta seção está dividida em três subseções, que discutem, respectivamente, a metodologia empregada nas estimações, a base de dados utilizada e os principais resultados obtidos. Por fim, são discutidos os determinantes das assimetrias encontradas, seguindo a mesma subdivisão utilizada na seção anterior. 


\section{REVISÃO DE LITERATURA}

\subsection{Choque de política monetária}

Uma grande parcela da variação na política monetária adotada pelo Banco Central pode ser entendida como uma resposta sistemática a mudanças no estado da economia. Dessa forma, parte da variação no instrumento de política monetária é endógena às variáveis do conjunto de informação do Banco Central. A fração da política monetária que é exógena a mudanças no estado da economia é entendida como um choque de política monetária.

Segundo Christiano et al (1999), a política monetária é normalmente formalizada como

$$
r_{t}=\psi\left(I_{t}\right)+\varepsilon_{t}^{s}
$$

onde $r_{t}$ é o instrumento de política monetária (i.e taxa de juros, agregado monetário, etc.) e $\psi$ é uma função linear que relaciona $r_{t}$ ao conjunto de informação $I_{t}$. A função $\psi$ corresponde à função de reação do Banco Central, ou seja, à parte sistemática da política monetária. A variável $\varepsilon_{t}^{S}$ representa o choque de política monetária, e captura qualquer desvio da regra $\psi$.

Christiano et al (1999) apresentam três possíveis interpretações econômicas para um choque de política monetária. Em primeiro lugar, $\varepsilon_{t}^{s}$ pode ser causado por mudanças exógenas nas preferências da autoridade monetária, como mudanças nos pesos relativos dados para as variáveis contidas em $I_{t}$. Em segundo lugar, o Banco Central pode desejar evitar o custo social de frustrar as expectativas dos agentes com relação à condução de política monetária, resultando em variações exógenas na política monetária ${ }^{1}$. Por fim, uma terceira fonte de variações exógenas estaria relaciona a fatores técnicos, como erros de medida presentes em bases de dados preliminares disponíveis no momento da tomada de decisão.

Com o surgimento de novas técnicas econométricas, principalmente com a introdução dos modelos VAR por Sims (1980), muita evidência empírica foi produzida na tentativa de se

\footnotetext{
${ }^{1}$ Ver Ball (1995) e Chari et al (1998).
} 
identificar um choque de política monetária e estimar seus efeitos em diversas variáveis macroeconômicas $^{2}$.

Para a economia brasileira, a metodologia de vetores autorregressivos também foi aplicada em estudos sobre os impactos de um choque de política monetária ${ }^{3}$. Dentre eles, destacamos Minella (2003), Céspedes et al (2008) e Arquete e Júnior (2003), que encontram evidência robusta de que uma inovação positiva de política monetária tem efeito negativo sobre a atividade. Minella (2003), trabalhando com três subamostras caracterizadas por inflação alta (janeiro de 1975 a julho de 1985), hiperinflação (agosto de 1985 a junho de 1994) e inflação baixa (setembro de 1994 a dezembro de 2000), conclui que o impacto de um choque monetário na atividade aumentou após o Plano Real.

Quanto à capacidade de um choque de política monetária reduzir a inflação, os artigos citados acima encontram evidências mistas. Minella (2003) destaca que choques monetários só passaram a afetar a taxa de inflação após a implementação do Plano Real. Contudo, os resultados obtidos para o período de estabilização da inflação não são conclusivos, apresentando resposta negativa e significante apenas para algumas especificações testadas. No mesmo sentido, Céspedes et al (2008) encontram resposta negativa da inflação, utilizando dados de março de 1999 a dezembro de 2004. Entretanto, o resultado não é robusto ao aumento do número de defasagens utilizadas no VAR. Arquete e Júnior (2003) conclui que choques positivos de política monetária elevam a taxa de inflação para sua especificação base e não apresentam efeitos estatisticamente significantes para especificações alternativas.

\subsection{Canais de transmissão}

Desagregações espaciais de um país podem responder de forma distinta a um choque comum de política monetária. Diferentes características de cada economia regional levam à presença mais preponderante de determinados canais de transmissão, o que resulta em respostas heterogêneas. Dessa forma, a compreensão de cada um desses canais de transmissão é essencial para o entendimento de assimetrias encontradas em uma economia.

\footnotetext{
${ }^{2}$ Ver, por exemplo, Christiano et al (1999), Sims (1992) e Bernanke e Mihov (1998).

${ }^{3}$ Para uma revisão mais completa dessa literatura, ver Céspedes et al (2008, p. 125).
} 
Dentre os canais de transmissão de política monetária, Mishkin (1996) enfatiza, entre outros, os canais de juros, crédito, câmbio e custos.

O canal de juros é um dos mecanismos de propagação mais abordados pela literatura, presente nos modelos Keynesianos IS-LM básicos. Uma redução exógena na taxa de juros nominal de curto prazo resulta em uma diminuição da taxa de juros real de curto prazo, que por sua vez leva à queda da taxa de juros real de longo prazo. Essa queda na taxa de juros real de longo prazo estimula a elevação do investimento em capital físico, em novas residências e do consumo de bens duráveis, aumentando o produto agregado.

A propagação da taxa de juros nominal de curto prazo para a taxa de juros real de curto prazo ocorre pela presença de preços rígidos. A rigidez de preços garante a redução do juro real de curto prazo, mesmo em modelos com expectativas racionais. Por sua vez, a hipótese das expectativas na estrutura a termo de juros garante que o juro real de longo prazo também seja afetado. A hipótese afirma que a taxa de juros de longo prazo é uma média dos juros esperados de curto prazo.

Diferenças na composição do setor produtivo podem acarretar em respostas regionais assimétricas a um choque de política monetária. A indústria de manufatura tende a ser mais sensível a mudanças exógenas na política do Banco Central devido, entre outros motivos, à dependência da demanda por bens duráveis à taxa de juros (CARLINO; DEFINA 1999). A mesma lógica aplica-se ao setor imobiliário (FRANCIS et al, 2012). Assim, regiões onde tais setores apresentam papel importante na economia local tendem a ser mais afetadas por inovações monetárias via canal de juros.

O fato de uma série de evidências empíricas não se encaixar na explicação do canal de juros $^{4}$ levou à elaboração de canais alternativos de transmissão de política monetária. Conhecido como canal de crédito, esse mecanismo de propagação visa complementar a explicação fornecida pela visão tradicional. A teoria baseia-se em fricções existentes no mercado financeiro, como informação imperfeita e contratos com enforcement custoso, para explicar como os mercados de crédito funcionam de modo a ampliar os efeitos da política monetária, em um mecanismo denominado acelerador financeiro.

O peso morto associado ao problema de agente principal entre credores e mutuários in-

\footnotetext{
${ }^{4}$ Ver Bernanke e Gertler (1995).
} 
troduz uma cunha entre o custo de oportunidade dos fundos que a firma pode obter internamente, como lucros retidos, e o custo de um empréstimo obtido externamente. Tal cunha, para a qual dá-se o nome de prêmio de financiamento externo, tem seu tamanho afetado por choques de política monetária através de dois canais: o balance sheet channel e o bank lending channel.

Segundo o balance sheet channel, uma elevação da taxa de juros deteriora a posição financeira dos mutuários, seja através do encarecimento da dívida de curto prazo e pós-fixada, seja pela redução do valor dos ativos da empresa, ou até pelo enfraquecimento da demanda por seus produtos. Consequentemente, o colateral que as firmas podem oferecer aos credores diminui, reduzindo assim sua capacidade de tomar empréstimos. Também baseando-se em falhas de mercado, o bank lending channel sustenta que os bancos comerciais não conseguem repor facilmente depósitos perdidos por outras formas de fundos líquidos, como certificados de depósito bancário e novas emissões de ações. Assim, uma operação de mercado aberto que drene reservas do sistema bancário acaba por limitar a oferta de crédito.

Ao contrário de firmas grandes, que podem obter fundos diretamente com os poupadores, as firmas pequenas são mais dependentes de intermediários financeiros. Quanto menor e menos estruturada for a empresa, mais sensível ela será às imperfeições de mercado existentes entre credor e mutuário. No mesmo sentido, quanto menores forem os bancos, mais dificuldade terão para obter fundos substitutos aos depósitos à vista. Assim, o canal de crédito tende a ser mais pronunciado em regiões com firmas e setor financeiro pouco desenvolvidos.

Outro canal de transmissão de política monetária importante opera através da taxa de câmbio. Um choque de política monetária que, por exemplo, reduza o juro real doméstico, torna os investimentos em moeda nacional menos atrativos do que os investimentos em moeda estrangeira. Essa mudança de preços relativos faz com que parte do capital externo saia do país, depreciando a taxa real de câmbio. O valor menor da moeda local estimula as exportações líquidas, o que contribui para a expansão do produto agregado. Setores como a indústria de manufaturas e mineração tendem a ser mais ligados à economia externa. Dessa forma, regiões nas quais tais setores apresentam presença importante tendem a ser mais sensíveis a um choque de política monetária devido à propagação mais intensa deste 
via canal de câmbio.

O canal de custo também pode ser responsável por assimetrias regionais. Sempre que o custo marginal da firma depender da taxa de juros, como por exemplo quando os fatores de produção são pagos antes do recebimento das receitas, um choque positivo de política monetária desloca a curva de oferta para a esquerda, reduzindo o produto e elevando os preços.

Além dos canais expostos acima, Francis et al (2012) ressaltam que outras características mais gerais da estrutura socioeconômica de uma região também podem contribuir para a propagação da política monetária. Uma mão de obra mais qualificada, por exemplo, teria mais facilidade em se deslocar entre setores diferentes, absorvendo mais facilmente o efeito de um choque de política monetária. O mesmo raciocínio vale para economias com um setor produtivo mais diverso. A flexibilidade do mercado de trabalho também pode ser um fator importante na propagação de uma inovação monetária. Mercados mais sindicalizados ou com maior percentual de empregos públicos tendem a ser mais rígidos e, portanto, menos sensíveis. Como o acesso a serviços financeiros depende do colateral que as famílias e firmas possuem, economias com renda per capita mais baixa e com percentual elevado de pessoas consideradas pobres tenderiam a ser menos sensíveis a mudanças exógenas na política do Banco Central. Adicionalmente, altas taxas de criminalidade podem desencorajar o empreendedorismo, reduzindo o número de agentes que utilizam linhas de crédito visando aproveitar oportunidades de negócios.

\subsection{Resposta regional}

O interesse da literatura econômica no estudo dos efeitos regionais da política monetária é antigo ${ }^{5}$. Contudo, a aplicação da metodologia VAR para se estimar os efeitos regionais de um choque de política monetária é mais recente, e ganha força após a introdução de uma moeda comum na Zona do Euro.

O artigo de Carlino e Defina (1999) é um dos primeiros trabalhos na área. Analisando a economia americana, as autores procuram responder duas questões essenciais para a compreensão da dinâmica regional da política monetária: (i) a resposta regional a um choque

\footnotetext{
${ }^{5}$ Ver, por exemplo, Miller (1978).
} 
comum de política monetária é assimétrica e (ii) quais fatores explicam essa heterogeneidade. Para tanto, são utilizadas as desagregações estaduais do real personal income, cobrindo o período entre o primeiro trimestre de 1958 e o quarto trimestre de 1992 . O instrumento de política monetária é modelado através da fed fund rate. O núcleo do índice nacional de preços ao consumidor, o índice de indicadores antecedentes e o índice de preços ao produtor também são utilizados no estudo.

Carlino e Defina (1999) encontram evidências de que os Estados americanos reagem de forma assimétrica a uma inovação na taxa de juros. O Estado de Michigan, por exemplo, é o mais sensível a um choque de política monetária. Sua resposta a uma elevação exógena de 1 p.p. na taxa de juros é 2.73 p.p. maior do que a resposta de Oklahoma, o menos sensível dos Estados. Agregando os Estados nas grandes regiões americanas ${ }^{6}$, os autores concluem que a região dos Grandes Lagos é a mais sensível a inovações de política monetária. No outro extremo, as regiões Sudoeste e das Montanhas Rochosas configuram entre as menos sensíveis.

Quanto aos possíveis determinantes das assimetrias encontradas, os autores concluem que o tamanho da resposta estadual está positivamente correlacionado com a proporção do produto de cada Estado correspondente à indústria de manufatura. Assim, dada a sensibilidade do setor manufatureiro à fed fund rate, conclui-se que o canal de juros é importante na determinação da heterogeneidade regional para os Estados americanos. Por outro lado, como não é encontrada correlação entre o tamanho das firmas e a resposta de cada Estado, descartou-se a importância do canal de crédito no nível estadual.

Após Carlino e Defina (1999), uma série de estudos investigou a existência de assimetrias regionais, tanto para os Estados Unidos, quanto para outros países. Sala (2001) divide os modelos VAR utilizados nessa literatura em dois grupos distintos: Multi-country e Specific-country. Um sistema VAR Multi-country inclui todas as desagregações de interesse em um único vetor. Já o sistema VAR Specific-country estima um modelo para cada desagregação de interesse.

Di Giacinto (2003) e Owyang e Wall (2003), por exemplo, trabalham com modelos VAR Multi-country para desagregações subnacionais dos Estados Unidos e encontram evidên-

\footnotetext{
${ }^{6}$ As regiões americanas são: New England, Mideast, Great Lakes, Plains, Southeast, Southwest, Rocky Mountain e Far West.
} 
cia favorável à presença de respostas regionais assimétricas. Também utilizando modelos VAR Multi-country, De Lucio e Izquierdo (1999) chegam à mesma conclusão para desagregações regionais da Espanha. Como exemplos de trabalhos que aplicam modelos VAR Specific-country, é possível citar, entre outros, Arnold e Vrugt (2002) e Bravo (2003), que encontram evidências de heterogeneidade na resposta regional a choques de política monetária para a Holanda e Chile, respectivamente.

Para o Brasil, diversos trabalhos também procuraram verificar a existência de assimetrias regionais na transmissão monetária. Dentre eles, destacam-se Vasconcelos e da Fonseca (2002), Araújo (2004), Bertanha e Haddad (2008), Rocha (2007) e Rocha et al (2011).

Vasconcelos e da Fonseca (2002) estimam um modelo VAR, incluindo em um mesmo vetor as desagregações da produção industrial para os Estados de São Paulo, Minas Gerais, Rio de Janeiro, Paraná, Rio Grande do Sul, Santa Catarina, Ceará, Pernambuco, Bahia e para a região Nordeste agregada, além da produção industrial nacional e a taxa Selic. As séries temporais abrangem o período de agosto de 1994 a dezembro de 2000. Os autores encontram que Pernambuco, São Paulo, Rio Grande do Sul e a região Nordeste apresentam, respectivamente, as maiores quedas na produção industrial após um choque de política monetária de 1 desvio padrão. Não é possível hierarquizar de forma conclusiva quais regiões seriam mais sensíveis ao choque, uma vez que os resultados são dispersos geograficamente.

Vasconcelos e da Fonseca (2002) também estimam um segundo modelo VAR, que inclui a taxa de juros Selic e o número índice de operações de crédito realizadas pelos bancos para o Brasil e para todas as Unidades Federativas do país, com exceção do Amapá, Sergipe, Tocantins e Distrito Federal. Os autores concluem que o crédito bancário dos Estados das regiões Norte, Nordeste e Centro-Oeste apresenta maior sensibilidade ao choque de política monetária.

Os resultados obtidos por estes autores devem ser vistos com ressalvas. Em primeiro lugar, não são incluídas no modelo as variáveis de inflação e de agregado monetário, dificultando a interpretação de uma das equações do modelo como sendo a função de reação do Banco Central. Em segundo, como aponta Rocha (2007), a estratégia de identificação do choque de política monetária é questionável. É utilizada a decomposição de Cholesky, no qual as variáveis são ordenadas conforme o critério alfabético. 
Araújo (2004) investiga se os Estados da região Sul são mais sensíveis a uma inovação de política monetária do que os Estados da Região Nordeste. Para tanto, utiliza modelos VECM Specific-country para os índices de produção industrial das regiões Nordeste e Sul, bem como para os Estados do Rio Grande do Sul, Santa Catarina, Paraná, Ceará, Bahia e Pernambuco. O vetor de cada modelo inclui ainda as seguintes variáveis: o índice de produção industrial nacional, um índice de inflação, a taxa de juro Selic e o agregado monetário M1 deflacionado. A base de dados cobre o período de setembro de 1994 até junho de 2002.

O autor conclui que a região Sul tende a reagir mais fortemente ao choque de política monetária, além de apresentar efeito máximo mais tardio quando comparado aos Estados do Nordeste. A utilização do procedimento Specific-country, contudo, apresenta fragilidades. Segundo Sala (2001), a interpretação do choque de política monetária obtido a partir dessa estratégia como sendo comum a todas as regiões pode ser prejudicada tanto por não considerar as inter-relações entre as regiões, quanto por diferenças nos choques iniciais.

Bertanha e Haddad (2008) aplicam o modelo VAR Espacial, proposto em Di Giacinto (2003), para a economia brasileira. O modelo VAR Espacial apresenta a vantagem de impor restrições às matrizes estimadas, diminuindo o problema de graus de liberdade. Sua estrutura permite estimar os efeitos de transbordamento, contemporâneos e defasados, entre as diferentes unidades espaciais. São testadas três especificações distintas. A primeira permite que o impacto de um choque de política monetária transborde de um Estado para outro de acordo com o peso desse Estado no comércio interestadual do outro. Uma segunda especificação permite transbordamento apenas entre Estados vizinhos. Por fim, é estimado um último modelo onde não há transbordamento interestadual.

Os autores constroem uma variável de estoque de emprego acumulando o valor líquido de novos postos de trabalho criados mês a mês (CAGED) sobre uma variável inicial de estoque (RAIS). Assim, conseguem trabalhar com desagregações para as 27 Unidades Federativas do Brasil, com dados que abrangem o período de janeiro de 1995 até dezembro de 2005. Seguindo uma abordagem Multi-country, todas as variáveis são incluídas no mesmo vetor, juntamente com o IPCA nacional, o agregado monetário M1 e a taxa de juros Selic. 
O estudo conclui que existem assimetrias regionais na transmissão da política monetária no Brasil, sendo as regiões Norte e Nordeste as mais sensíveis a uma inovação no instrumento de política do Banco Central. O efeito transbordamento, contemporâneo e defasado, é estatisticamente significante. Ao transitar do modelo baseado no fluxo interestadual de comércio para o modelo no qual inexiste transbordamento, passando pelo modelo baseado na vizinhança dos Estados, os impactos de política monetária tornamse, em média, mais fortes e dispersos. O Estado de São Paulo destaca-se por repassar o impacto sofrido por sua economia para a maioria das outras Unidades Federativas.

Rocha (2007) estima o impacto de um choque de política monetária através de um Modelo de Fatores Dinâmicos Generalizado (FORNI et al, 2000), guiando-se pelo estudo de Sala (2001). O Modelo de Fatores Dinâmicos Generalizado representa a dinâmica de um conjunto de variáveis pela combinação de um número reduzido de choques comuns. Dessa forma é possível trabalhar com um conjunto de dados bastante amplo sem incorrer no problema da dimensionalidade.

São utilizados os índices de produção industrial, IPCA e volume real de crédito bancário para os Estados de São Paulo, Minas Gerais, Rio de Janeiro, Rio Grande do Sul, Paraná, Pernambuco, Ceará e Bahia, cobrindo o período entre janeiro de 1995 e novembro de 2003. A taxa de juros Selic também é incluída no vetor de variáveis de interesse, totalizando 25 variáveis.

O autor conclui que uma inovação positiva de política monetária tende a reduzir a atividade dos Estados brasileiros no curto prazo, mas seus efeitos são nulos no longo prazo. A queda na produção estadual acumula-se até seis meses após o choque, extinguindo-se em seguida. As evidências encontradas apontam para a existência de assimetrias regionais na transmissão de política monetária. Os Estados da Bahia e Paraná aparecem como os mais vulneráveis, enquanto São Paulo, Pernambuco e Minas Gerais seriam os menos sensíveis ao choque.

Por fim, Rocha et al (2011) estimam um modelo VAR estrutural para cada um dos seguintes Estados brasileiros: Amazonas, Pará, Ceará, Pernambuco, Bahia, Minas Gerais, Espírito Santos, Rio de Janeiro, São Paulo, Paraná, Santa Catarina, Rio Grande do Sul e Goiás. Em cada modelo também é incluído o índice de produção industrial nacional, o IPCA e a taxa de juros Selic. A base de dados abrange o período de janeiro de 1995 a 
novembro de 2010, com exceção dos modelos para o Amazonas, Goiás e Pará, cuja série de produção industrial começa em 2002.

Os autores também encontram evidência da existência de assimetrias regionais na resposta a um choque de política monetária. Os Estados da Amazônia e Pernambuco são os mais sensíveis ao choque. Uma elevação exógena de $1 \%$ na Selic reduz a atividade dos dois Estados em $0.058 \%$ e $0.051 \%$, respectivamente. Dentre os Estados menos sensíveis destacam-se Santa Catarina e Espírito Santo. Os resultados obtidos não apontam para nenhum padrão regional claro, sugerindo que semelhanças entre os Estados seriam mais importantes para explicar sua sensibilidade do que uma dinâmica regional propriamente dita.

Vale lembrar que, como já mencionado anteriormente, a utilização do procedimento Specificcountry pode prejudicar a interpretação de um choque de política monetária como sendo comum a todas as unidades regionais.

É importante mencionar que dentro da literatura nacional o problema da falta de dados é latente. Poucas séries possuem, além de um número elevado de observações, desagregação para todas as Unidades Federativas. Como é possível observar na breve revisão acima, essa restrição faz com que os autores trabalhem com especificações e níveis de agregação regional diferentes, já que o modelo VAR consome graus de liberdade de forma bastante rápida, à medida que novas variáveis são adicionadas ao sistema. A maioria dos trabalhos analisados não abrange uma desagregação exaustiva do território nacional, o que, segundo Bertanha e Haddad (2008), pode enviesar os resultados. Ademais, optar pela abordagem Specific-country para mitigar o problema de dimensionalidade prejudica a identificação do choque monetário comum.

O VAR Bayesiano mostra-se adequado ao caso brasileiro, justamente por permitir trabalhar com um grande número de séries sem incorrer no problema da dimensionalidade presente na abordagem frequentista. Dessa forma, a escolha da metodologia Bayesiana se justifica por possibilitar incluir em um mesmo vetor as 27 Unidades Federativas brasileiras.

Por fim, é necessário ressaltar que apesar das evidências encontradas a favor da existência de assimetrias regionais na transmissão monetária, a literatura nacional avançou pouco 
no sentido de entender quais fatores determinam tal heterogeneidade. Vasconcelos e da Fonseca (2002) fazem uma análise descritiva da distribuição estadual da participação da indústria no valor adicionado bruto, percentual de pequenas firmas na indústria de transformação, distribuição de agências bancárias, distribuição de operações de crédito, dentre outras variáveis. De posse dessas estatísticas, Vasconcelos e da Fonseca (2002) conjecturam sobre os possíveis determinantes da heterogeneidade regional na transmissão monetária. Apesar de constituir um primeiro passo importante, o estudo não se baseia em uma análise econométrica mais sólida, o que impede os autores de testarem empiricamente suas hipóteses.

Investigar, dentro de um arcabouço quantitativo mais rigoroso, quais fatores determinam as assimetrias regionais é essencial para a compreensão da dinâmica da política monetária para além da agregação nacional. Apenas recentemente é dado esse passo na literatura brasileira, com o trabalho de Rocha et al (2011). Os autores encontram evidências pouco conclusivas de que os canais de juros e de crédito são importantes para explicar tais assimetrias, muitas vezes chegando a resultados opostos ao indicado pela teoria.

Para o canal de juros, obtém-se que a proporção de estabelecimentos industriais e de estabelecimentos da indústria extrativa, em relação ao total de estabelecimentos, são ambas negativamente correlacionadas com a sensibilidade estadual. Não encontra-se correlação significante entre a proporção de estabelecimentos da indústria de transformação e a sensibilidade estadual. Para o canal de crédito, conclui-se que Estados com maior volume de depósitos bancários são mais sensíveis ao choque de política monetária. Contudo, o tamanho das firmas e bancos são positivamente correlacionados com a sensibilidade dos Estados.

Rocha et al (2011) testam também a presença do canal sociodemográfico, chegando a resultados em linha com o indicado pela teoria. Estados com maior densidade demográfica, maior estoque de capital humano e maior diversidade no setor industrial apresentam menor sensibilidade ao choque de política monetária.

Os resultados obtidos devem ser vistos com cautela, dado o número reduzido de observações utilizadas nas regressões. Como Rocha et al (2011) não trabalham com todos os Estados brasileiros, suas regressões contêm apenas 13 observações. Dentro do arcabouço 
frequentista, essa limitação acarreta um grave problema de consistência dos parâmetros estimados, tornando-os muito pouco confiáveis.

Adicionalmente, a escolha das diferentes especificações testadas é arbitrária. Os autores testam 7 especificações distintas, que diferem umas das outras pela exclusão de um grupo determinado de variáveis explicativas. Procedimentos como este são recorrentes dentro da literatura frequentista. Quanto maior e mais incerto é o conjunto de covariadas que potencialmente podem explicar determinada variável, mais arbitrária se torna a escolha de diferentes especificações. Esse problema é latente na questão abordada nesse estudo, uma vez que o conjunto dos possíveis canais de transmissão e características estaduais que poderiam determinar as assimetrias encontradas é bastante amplo.

Dessa forma, faz-se necessário avançar no estudo dos determinantes das assimetrias regionais em relação a um choque de política monetária. Novamente, o arcabouço Bayesiano provém técnicas que permitem contornar os problemas citados acima. A opção de abordar a questão através da metodologia denominada Bayesian Model Averaging justifica-se não só pelo fato de as técnicas Bayesianas oferecerem uma solução à questão da dimensionalidade, mas também por permitir modelar formalmente as incertezas relacionadas a quais variáveis explicativas devem ser incluídas nas estimações.

Francis et al (2012) serão a principal referência teórica do presente estudo. Os autores utilizam metodologias Bayesianas na tentativa de investigar tanto se as regiões metropolitanas americanas apresentam assimetrias na transmissão de um choque de política monetária, quanto quais os determinantes dessa heterogeneidade.

Como é empregada uma abordagem Multi-country, dados de emprego para 105 cidades americanas são incluídos em um mesmo vetor. Dessa forma, Francis et al (2012) utilizam um VAR Bayesiano para contornar o problema de dimensionalidade presente na estimação. As evidências encontradas apontam para a presença de forte heterogeneidade entre regiões metropolitanas, mesmo para unidades geograficamente próximas ou pertencentes ao mesmo Estado.

Para a questão dos determinantes das assimetrias regionais é utilizado o Bayesian Model Averaging, permitindo formalizar a incerteza sobre o modelo adequado para a pergunta em mãos. Francis et al (2012) concluem que características de propagação mais abran- 
gentes são mais importantes para explicar as assimetrias no nível da cidade do que os canais tradicionais de juros e crédito. A densidade populacional parece ser o principal fator explicando as variações entre cidades. Contudo, variáveis como a proporção da mão de obra total que está empregada da indústria de manufatura parecem mais robustas a incertezas relacionadas à estimação do modelo VAR. 


\section{EFEITO REGIONAL DE POLÍTICA MONETÁRIA}

A metodologia utilizada é baseada no procedimento de duas etapas proposto por Carlino e Defina (1999). Em primeiro lugar, estima-se o impacto de um choque de política monetária através de um modelo SVAR. As restrições são impostas ao modelo SVAR de forma que uma das $m$ equações do vetor autorregressivo tenha a interpretação dada à função de reação do Banco Central. Estima-se o impacto de um choque de política monetária $\varepsilon_{t}^{s}$ na atividade das regiões de interesse através da construção das funções de impulso resposta. A segunda etapa do procedimento consiste em regredir uma cross-section de variáveis proxy para os canais de transmissão de política monetária em alguma variável que capture a sensibilidade da atividade regional ao choque $\varepsilon_{t}^{s}$. Essa variável é construída a partir das funções de impulso resposta estimadas na primeira etapa (i.e. resposta máxima, resposta acumulada, etc). Nesta seção será abordada a metodologia utilizada na primeira etapa. A segunda etapa é exposta na próxima seção.

Os modelos VAR foram propostos por Sims (1980) como uma alternativa aos modelos de equações simultâneas predominantes à época. A metodologia visa estudar a interação entre variáveis econômicas ao longo do tempo com uma estrutura predominantemente estatística, evitando a imposição de restrições pouco realistas. Contudo, a estrutura pouco restritiva dos modelos VAR implica em um grande número de parâmetros a serem estimados, mesmo para sistemas de tamanho moderado. Dessa forma, é alto o risco de sobreparametrização, dado que as séries temporais macroeconômicas, normalmente, apresentam dimensão insuficiente para que os parâmetros possam ser estimados de forma confiável (BANBURA et al, 2010). A desagregação da variável de interesse em diversas unidades regionais apenas agrava o problema, uma vez que o número de parâmetros cresce de forma explosiva e os graus de liberdade são consumidos rapidamente à medida que inserimos novas variáveis (BERTANHA; HADDAD, 2008; ROCHA, 2007).

Uma forma de contornar esse problema é a utilização do VAR Bayesiano (BVAR) ${ }^{7}$, que permite combinar informações obtidas a partir dos dados, com informações provenientes do próprio pesquisador. Recentemente, uma série de estudos têm se utilizado do BVAR para estimar modelos com um grande número de variáveis. Banbura et al (2010), por

\footnotetext{
${ }^{7}$ Para detalhes técnicos de como o BVAR contorna o problema de dimensionalidade, ver De Mol et al (2008) e Banbura et al (2010).
} 
exemplo, estimam um VAR com 131 variáveis, contendo, além de séries macroeconômicas, dados setoriais, variáveis financeiras e informações conjunturais.

Apesar da introdução de novos parâmetros no modelo aumentar o $R^{2}$ (quando não ajustado pelos graus de liberdade), a variância dos parâmetros também aumentará, tornando as estimações da função de impulso resposta mais erráticas. Contudo, na especificação Bayesiana do modelo esse trade-off desaparece. Existem limites para a extensão na qual novas variáveis podem ser incluídas, mas esses limites são computacionais e não relacionados aos graus de liberdade (LITTERMAN, 1986). Litterman (1986) compara o erro quadrático médio (EQM) dos coeficientes estimados pela metodologia Bayesiana com o EQM dos coeficientes do modelo sem prior, onde as variáveis explicativas são escolhidas pelo pesquisador de forma a obter um modelo parcimonioso, e encontra que o EQM do modelo Bayesiano é menor para todos os casos e amostras testadas.

\subsection{Metodologia}

\subsubsection{SVAR Bayesiano: $O$ caso exatamente identificado ${ }^{8}$}

O modelo VAR estrutural (SVAR) é geralmente escrito como

$$
A^{\prime} y_{t}=C+\sum_{l=1}^{p} A_{l}^{\prime} y_{t-l}+\varepsilon_{t}, \quad \forall t=1, \ldots, T
$$

onde $A$ e $A_{l}$ são matrizes de parâmetros $m \times m, C$ é um vetor $m \times 1$ de constantes, $y_{t}$ é um vetor $m \times 1$ que contém $m$ variáveis endógenas, $\varepsilon_{t}$ é um vetor $m \times 1$ de choques estruturais, $p$ é a quantidade de defasagens consideradas no modelo e $T$ é o tamanho da amostra. Cada coluna de $A$ e $A_{l}$ contém os parâmetros de uma das $m$ equação do sistema. Os choques estruturais têm distribuição Normal com média zero e variância unitária,

$$
\varepsilon_{t} \sim N(\underset{m \times 1}{0}, \underset{m \times m}{I})
$$

Pré multiplicando o modelo (2) por $A^{\prime-1}$, obtém-se o modelo VAR na forma reduzida

\footnotetext{
${ }^{8}$ Ver Canova (2007) e Koop e Korobilis (2010).
} 


$$
y_{t}=c+\sum_{l=1}^{p} B_{l}^{\prime} y_{t-l}+e_{t}
$$

onde $B_{l}=A^{\prime-1} A_{l}^{\prime}$ é a matriz $m \times m$ de coeficientes, $c=A^{\prime-1} C$ é um vetor $m \times 1$ de constantes e $e_{t}=A^{\prime-1} \varepsilon_{t}$ é um vetor $m \times 1$ de erros. Com as hipóteses feitas em (3), $e_{t} \sim N(0, \Sigma)$, onde

$$
\Sigma=\left(A A^{\prime}\right)^{-1}
$$

O modelo VAR também pode ser descrito como uma Normal multivariada. Seja y um vetor $m T \times 1$, no qual primeiramente são colocadas as $T$ observações da primeira variável, depois as $T$ observações da segunda variável, etc. Defina ainda $x_{t}=\left(1, y_{t-1}^{\prime}, \ldots, y_{t-p}^{\prime}\right)$ e

$$
X=\left[\begin{array}{c}
x_{1} \\
x_{2} \\
\vdots \\
x_{T}
\end{array}\right]
$$

Seja $k=1+m p$ o número de coeficientes em cada equação do VAR, então $x_{t}$ é um vetor $1 \times k$ e $X$ é uma matriz $T \times k$.

Por fim, defina $B=\left[C, B_{1} \ldots B_{p}\right]^{\prime}$ e $\beta=v e c(B)$. O modelo VAR pode ser descrito como

$$
y=\left(I_{m} \otimes X\right) \beta+\varepsilon
$$

onde $\varepsilon \sim N\left(0, \Sigma \otimes I_{m}\right)$.

Usando a versão multivariada do modelo, temos que a função de verossimilhança do $\operatorname{VAR}(\mathrm{p}), p(y \mid \beta, \Sigma)$, é proporcional a:

$$
\left|\Sigma \otimes I_{T}\right|^{-0.5} \exp \left\{-0.5\left(y-\left(I_{m} \otimes X\right) \beta\right)^{\prime}\left(\Sigma^{-1} \otimes I_{T}\right)\left(y-\left(I_{m} \otimes X\right) \beta\right)\right\}
$$


É possível demonstrar que essa função de verossimilhança pode ser dividida em duas partes: a distribuição de $\beta$ dado $\Sigma$ e a distribuição de $\Sigma^{-1}$. Para tornar essa divisão mais clara, observe que

$$
\begin{gathered}
\left(y-\left(I_{m} \otimes X\right) \beta\right)^{\prime}\left(\Sigma^{-1} \otimes I_{T}\right)\left(y-\left(I_{m} \otimes X\right) \beta\right)= \\
=\left(\Sigma^{-0.5} \otimes I_{T}\right)\left(y-\left(I_{m} \otimes X\right) \beta\right)^{\prime}\left(\Sigma^{-0.5} \otimes I_{T}\right)\left(y-\left(I_{m} \otimes X\right) \beta\right)= \\
=\left[\left(\Sigma^{-0.5} \otimes I_{T}\right) y-\left(\Sigma^{-0.5} \otimes X\right) \beta\right]^{\prime}\left[\left(\Sigma^{-0.5} \otimes I_{T}\right) y-\left(\Sigma^{-0.5} \otimes X\right) \beta\right]
\end{gathered}
$$

Além disso,

$$
\left(\Sigma^{-0.5} \otimes I_{T}\right) y-\left(\Sigma^{-0.5} \otimes X\right) \beta=\left(\Sigma^{-0.5} \otimes I_{T}\right) y-\left(\Sigma^{-0.5} \otimes X\right) \hat{\beta}+\left(\Sigma^{-0.5} \otimes X\right)(\hat{\beta}-\beta)
$$

onde $\hat{\beta}=\left(\Sigma^{-1} \otimes X^{\prime} X\right)^{-1}\left(\Sigma^{-1} \otimes X\right)^{\prime} y$. Dessa forma,

$$
\begin{gathered}
\left(y-\left(I_{m} \otimes X\right) \beta\right)^{\prime}\left(\Sigma^{-1} \otimes I_{T}\right)\left(y-\left(I_{m} \otimes X\right) \beta\right)= \\
=\left[\left(\Sigma^{-0.5} \otimes I_{T}\right) y-\left(\Sigma^{-0.5} \otimes X\right) \hat{\beta}\right]^{\prime}\left[\left(\Sigma^{-0.5} \otimes I_{T}\right) y-\left(\Sigma^{-0.5} \otimes X\right) \hat{\beta}\right] \\
+(\hat{\beta}-\beta)^{\prime}\left(\Sigma^{-1} \otimes X^{\prime} X\right)(\hat{\beta}-\beta)
\end{gathered}
$$

Colocando todas as partes de volta na função de verossimilhança, temos

$$
p(y \mid \beta, \Sigma) \propto\left|\Sigma \otimes I_{T}\right|^{-0.5} \exp \left\{-0.5(\beta-\hat{\beta})^{\prime}\left(\Sigma^{-1} \otimes X^{\prime} X\right)(\beta-\hat{\beta})\right.
$$




$$
\begin{gathered}
\left.-0.5\left[\left(\Sigma^{-0.5} \otimes I_{T}\right) y-\left(\Sigma^{-0.5} \otimes X\right) \hat{\beta}\right]^{\prime}\left[\left(\Sigma^{-0.5} \otimes I_{T}\right) y-\left(\Sigma^{-0.5} \otimes X\right) \hat{\beta}\right]\right\} \\
=|\Sigma|^{-0.5 k} \exp \left\{-0.5(\beta-\hat{\beta})^{\prime}\left(\Sigma^{-1} \otimes X^{\prime} X\right)(\beta-\hat{\beta})\right\} \\
\times|\Sigma|^{-0.5(T-k)} \exp \left\{-0.5 \operatorname{tr}\left(\left(\Sigma^{-0.5} \otimes I_{T}\right) y\right.\right. \\
\left.\left.-\left(\Sigma^{-0.5} \otimes X\right) \hat{\beta}\right)^{\prime}\left(\left(\Sigma^{-0.5} \otimes I_{T}\right) y-\left(\Sigma^{-0.5} \otimes X\right) \hat{\beta}\right)\right\}
\end{gathered}
$$

Observe que a função de verossimilhança foi decomposta em uma multiplicação de uma densidade Normal para $\beta$ condicional em $\Sigma$, com média $\hat{\beta}$ e variância $\Sigma \otimes\left(X^{\prime} X\right)^{-1}$, e uma densidade Wishart para $\Sigma^{-1}$ como uma matriz de escala $\left[\left(y-\left(I_{m} \otimes X\right) \hat{\beta}\right)^{\prime}\left(y-\left(I_{m} \otimes X\right) \hat{\beta}\right)\right]^{-1}$ e $T-k-m-1$ graus de liberdade:

$$
p(y \mid \beta, \Sigma) \propto \mathbb{N}(\beta \mid \hat{\beta}, \Sigma, X, y) \times \mathbb{W}\left(\Sigma^{-1} \mid y, X, \hat{\beta}, T-k-m-1\right)
$$

Um vez escolhida a prior $p(\beta, \Sigma)$ para compor o VAR Bayesiano, a posterior $p(\beta, \Sigma \mid y)$ estará definida. Quando o modelo (2) for exatamente identificado, para cada amostra sorteada de $p(\beta, \Sigma \mid y)$ é possível, a partir do modelo na forma reduzida (4) e de (5), obter um mapeamento biunívoco ente $A$ e $\Sigma^{9}$. Assim, para cada sorteio da distribuição $p(\beta, \Sigma \mid y)$ é possível recuperar os parâmetros estruturais e construir a função de impulso resposta. Após repetir o procedimento $n^{*}$ vezes, obtém-se $n^{*}$ funções de impulso resposta, o que permite calcular a média, a mediana ou qualquer percentil de interesse.

\footnotetext{
${ }^{9}$ Existem alguns casos especiais onde essa relação biunívoca deixa de existir, mesmo em sistemas exatamente identificados. Ver Bekker e Pollock (1986) e Sims e Zha (1999).
} 


\subsubsection{SVAR Bayesiano: $O$ caso sobre identificado ${ }^{10}$}

Esse procedimento de estimação indireto, onde a matriz $A$ não é modelada explicitamente (i.e. não possui prior) só é válido quando a posterior restrita e irrestrita dos parâmetros do modelo na forma reduzida têm o mesmo formato. Essa hipótese é violada, por exemplo, nos modelos sobre identificados. Nesses casos, a matriz de covariância $\Sigma$ torna-se restrita e a sua posterior não apresenta mais o mesmo formato da posterior da matriz de covariância irrestrita. Assim, faz-se necessário introduzir $A$ explicitamente na estimação, definindo uma prior $p\left(A, A_{1}, \ldots, A_{p}\right)$ e obtendo uma posterior $p\left(A, A_{1}, \ldots, A_{p} \mid y\right)$.

Voltando ao modelo estrutural (2) é possível reescrevê-lo como

$$
y_{t}^{\prime} A=x_{t} F+\varepsilon_{t}^{\prime}
$$

onde $F^{\prime}=\left[A_{1}^{\prime} \ldots A_{p}^{\prime} C\right]$ é uma matriz $m \times k$.

Para $1 \leqslant i \leqslant m$, defina a $i$-ésima coluna de $A$ e $F$ como $a_{i}$ e $f_{i}$, respectivamente. Seja $Q_{i}$ uma matriz $m \times m$ de posto $q_{i}$ e $R_{i}$ uma matriz $k \times k$ de posto $r_{i}$. As restrições consideradas pela literatura em questão podem ser resumidas como ${ }^{11}$

$$
\begin{array}{rr}
Q_{i} a_{i}=0 & i=1, \ldots, m . \\
R_{i} f_{i}=0 & i=1, \ldots, m .
\end{array}
$$

Seja $U_{i}$ uma matriz $m \times q_{i}$ cujas colunas formam uma base ortonormal para o espaço nulo de $Q_{i}$ e defina $V_{i}$ como uma matriz $k \times r_{i}$ cujas colunas formam uma base ortonormal para o espaço nulo de $R_{i}$. As colunas $a_{i}$ e $f_{i}$ satisfazem (10) e (11) se, e somente se, existir um vetor $b_{i}, q_{i} \times 1$, e um vetor $g_{i}, r_{i} \times 1$, tal que:

$$
\begin{gathered}
a_{i}=U_{i} b_{i} \\
f_{i}=V_{i} g_{i}
\end{gathered}
$$

\footnotetext{
${ }^{10}$ Seguiremos a notação de Waggoner e Zha (2003). Outras referências podem ser encontradas em Sims e Zha (1998) e Del Negro e Schorfheide (2011).

${ }^{11}$ As restrições consideradas aqui não englobam restrições entre equações para o modelo estrutural.
} 
Seja $b=\left[b_{1}^{\prime} \ldots b_{m}^{\prime}\right]^{\prime}, g=\left[g_{1}^{\prime} \ldots g_{m}^{\prime}\right]^{\prime}$ e $Y=\left[y_{1} \ldots y_{T}\right]^{\prime}$. A função de verossimilhança é proporcional a

$$
\begin{gathered}
\left|\operatorname{det}\left[U_{1} b_{1}|\cdots| U_{m} b_{m}\right]\right|^{T} \exp \left\{-\frac{1}{2} \sum_{i=1}^{m}\left(b_{i}^{\prime} U_{i}^{\prime} Y^{\prime} Y U_{i} b_{i}\right.\right. \\
\left.\left.-2 g_{i}^{\prime} V_{i}^{\prime} X^{\prime} Y U_{i} b_{i}+g_{i}^{\prime} V_{i}^{\prime} X^{\prime} X V_{i} g_{i}\right)\right\}
\end{gathered}
$$

A identificação do sistema será obtida seguindo a estrutura proposta por Francis et al (2012), na qual o vetor de variáveis endógenas e a matriz de coeficientes contemporâneos são particionados da seguinte maneira:

$$
A=\left[\begin{array}{ll}
D & A_{21} \\
0 & A_{22}
\end{array}\right], y_{t}=\left[\begin{array}{l}
\operatorname{reg}_{t} \\
a g r_{t}
\end{array}\right]
$$

onde $r e g_{t}$ é o vetor de variáveis regionais, $a g r_{t}$ é o vetor de variáveis agregadas. $D$ é uma matriz diagonal, e $A_{21}$ e $A_{22}$ são partições irrestritas de $A$.

Esse esquema de identificação baseia-se em Christiano et al (1999) para as variáveis agregadas e em Carlino e Defina (1999) para o sistema regional. Assume-se que choques estaduais afetam contemporaneamente apenas o seu local de origem e as variáveis agregadas. Já os choques nas variáveis agregadas afetam as variáveis regionais com um período de defasagem, mas afetam as demais variáveis agregadas contemporaneamente.

\subsubsection{Prior}

A prior de Minnesota (DOAN et al, 1984; LITTERMAN, 1986) é amplamente usada na literatura, uma vez que facilita a escolha dos hiper parâmetros e diminui os custos computacionais (KOOP; KOROBILIS, 2010). A prior de Minnesota supõe uma prior não informativa para a matriz de covariância $\Sigma$ e uma distribuição Normal para os coeficientes $\beta$. Refletindo a crença a priori de que as variáveis se comportam, na média, como um passeio aleatório, $E(\beta)=0$ para todos os coeficientes do vetor, com exceção da primeira defasagem da própria variável que possui média 1 . 
Na aplicação específica deste trabalho, serão utilizadas algumas séries que não se comportam como um passeio aleatório. Mais especificamente, as séries regionais de criação líquida de novos empregos assemelham-se mais a um processo autorregressivo estacionário. Dessa forma, a prior dessas séries foi modificada, centralizando sua distribuição ao redor de um processo $\mathrm{AR}(1)$ com coeficiente 0,7 .

Adicionalmente, $\operatorname{var}(\beta)$ é uma matriz diagonal que possui apenas três elementos distintos: a variância dos coeficientes das defasagens da própria variável, a variância dos coeficientes das defasagens das outras variáveis e a variância da constante, na qual as duas primeiras decrescem conforme $p$ aumenta, refletindo a crença a priori de que os coeficientes de defasagens mais distantes estão mais concentrados ao redor do zero.

Sims e Zha (1998) incorporaram a ideia da prior de Minnesota dentro do arcabouço dos modelos VAR estruturais. Dessa forma, a prior para modelos estruturais pode ser escrita como

$$
a_{i} \sim N\left(0, \bar{S}_{i}\right)
$$

$\mathrm{e}$

$$
f_{i} \mid a_{i} \sim N\left(\bar{P}_{i} a_{i}, \bar{H}_{i}\right)
$$

Para reproduzir a ideia de que as variáveis do modelo na forma reduzida (4) $B=F A^{-1}$ estão centradas ao redor de um passeio aleatório, $\bar{P}_{i}$ é definida como um para a própria defasagem e zero para as demais. Dessa forma

$$
E[F \mid A]=\bar{P}_{i} a_{i}=\left[\begin{array}{c}
A \\
0 \\
\vdots \\
0
\end{array}\right]
$$

A matriz de covariância de $f_{i}$ dado $a_{i}$ segue o padrão da prior de Minnesota, de forma que $\bar{H}_{i}$ é diagonal, e a variância do coeficiente da defasagem $p$ da variável $j$ na equação $m$ é dado por 


$$
\left[\frac{\lambda_{0} \lambda_{1}}{\sigma_{j} p^{\lambda_{3}}}\right]^{2}
$$

O hiper parâmetro $\lambda_{0}$ controla o quão concentrada é a prior no geral. Já $\lambda_{1}$ controla as crenças sobre a hipótese de que as variáveis estão centradas ao redor de um passeio aleatório. Por fim, $\lambda_{3}$ controla a taxa na qual a variância da prior diminui conforme as defasagens aumentam. Em Litterman (1986) a variância acima é ponderada por $\frac{\sigma_{i}}{\sigma_{j}}$, o que permite ajustar a escala da variância para o fato da unidade de medida não ser igual entre as $m$ variáveis endógenas. Na versão de Sims e Zha (1998) a variância da prior é ponderada por $\frac{1}{\sigma_{j}}$, já que a variância da equação $i$ é, pela hipótese (3), igual a um. Outra diferença entre as duas priors reside no fato de não haver diferença entre a variância dos coeficientes da própria defasagem e das defasagens das outras variáveis. Isso ocorre porque não existe o conceito de "própria defasagem" no modelo estrutural, já que todas as variáveis entram contemporaneamente em cada equação via a matriz $A$.

Na especificação de Sims e Zha (1998), a prior da constante apresenta média zero e variância $\lambda_{0} \lambda_{4}$, onde $\lambda_{4}$ é um hiper parâmetro à parte, que controla a concentração da distribuição ao redor de zero.

Também foram impostas priors para a ordem de integração e para a possibilidade de cointegração entre as variáveis, através da introdução de observações dummy como em Doan et al (1984), Sims (1993) e Sims e Zha (1998). Observações dummy são dados artificialmente criados e introduzidos na regressão, gerando um distribuição posterior idêntica a que seria obtida com a especificação de uma prior. É possível, por exemplo, gerar um resultado idêntico ao obtido através da prior de Minnesota, apenas com a introdução de observações dummy ${ }^{12}$. Com a utilização de observações dummy, mais dois hiper parâmetros são introduzidos ao modelo. $\mu_{5}$ controla a prior referente à ordem de integração das séries e $\mu_{6}$ determina a prior para a possibilidade de cointegração. Os valores dos hiper parâmetros foram escolhidos seguindo Francis et al (2012), e podem ser encontrados na tabela 1 .

Ao aplicar as transformações (12) e (13) o que se faz na prática é isolar apenas os parâmetros aos quais não foram impostas as restrições de exclusão. Assim, podemos escrever

\footnotetext{
${ }^{12}$ Para uma explicação completa e didática, ver Blake e Mumtaz (2012).
} 
Tabela 1: Hiper Parâmetros Prior

\begin{tabular}{ccl}
\hline Hiper Parâmetros & Valor & Interpretação \\
\hline \hline$\lambda_{0}$ & 1 & Controla o quão concentrada é a prior no geral \\
$\lambda_{1}$ & 0.2 & Controla o quão concentrado ao redor da hipótese de passeio aleatório é a prior \\
$\lambda_{3}$ & 1 & Direciona a taxa de contração da prior conforme as defasagens aumentam \\
$\lambda_{4}$ & 1 & Regula a prior relacionada à constante \\
$\mu_{5}$ & 1 & Referente à ordem de integração das variáveis \\
$\mu_{6}$ & 1 & Referente à cointegração entre as variáveis \\
\hline
\end{tabular}

a prior em função apenas das variáveis $b_{i}$ e $g_{i}$, que são da forma

$$
a_{i}=U_{i} b_{i}
$$

$$
f_{i}=V_{i} g_{i}
$$

A prior para $b_{i}$ e $g_{i}$ pode ser escrita como

$$
b_{i} \sim N\left(0, \tilde{S}_{i}\right)
$$

$$
g_{i} \mid b_{i} \sim N\left(\tilde{P}_{i} b_{i}, \tilde{H}_{i}\right)
$$

onde

$$
\begin{gathered}
\tilde{H}_{i}=\left(V_{i}^{\prime} \bar{H}_{i}^{-1} V_{i}\right)^{-1} \\
\tilde{P}_{i}=\tilde{H}_{i} V_{i}^{\prime} \bar{H}_{i}^{-1} \bar{P}_{i} U_{i} \\
\tilde{S}_{i}=\left(U_{i}^{\prime} \bar{S}_{i}^{-1} U_{i}+U_{i}^{\prime} \bar{P}_{i}^{\prime} \bar{H}_{i}^{-1} \bar{P}_{i} U_{i}-\tilde{P}_{i}^{\prime} \tilde{H}_{i}^{-1} \tilde{P}_{i}\right)^{-1}
\end{gathered}
$$

\subsubsection{Posterior}

Ao juntar a prior de $b_{i}$ e $g_{i}$ dada por (21) e (22) com a verossimilhança dada por (14) temos a seguinte distribuição posterior 


$$
p\left(b_{1}, \ldots, b_{m}, g \mid X, Y\right)=p\left(b_{1}, \ldots, b_{m} \mid X, Y\right) \prod_{i=1}^{m} p\left(g_{i} \mid b_{i}, X, Y\right)
$$

onde

$$
\begin{gathered}
p\left(b_{1}, \ldots, b_{m} \mid X, Y\right) \propto \mid \operatorname{det}\left[U_{1} b_{1}|\ldots| U_{m} b_{m}\right]^{T} \exp \left(-\frac{T}{2} \sum_{i=1}^{m} b_{i}^{\prime} S_{i}^{-1} b_{i}\right) \\
p\left(g_{i} \mid b_{i}, X, Y\right)=N\left(P_{i} b_{i}, H_{i}\right)
\end{gathered}
$$

e

$$
\begin{gathered}
H_{i}=\left(V_{i}^{\prime} X^{\prime} X V_{i}+\tilde{H}_{i}^{-1}\right)^{-1} \\
P_{i}=H_{i}\left(V_{i}^{\prime} X^{\prime} Y U_{i}+\tilde{H}_{i}^{-1} \tilde{P}_{i}\right) \\
S_{i}=\left(\frac{1}{T}\left(U_{i}^{\prime} Y^{\prime} Y U_{i}+\tilde{S}_{i}^{-1}+\tilde{P}_{i}^{\prime} \tilde{H}_{i}^{-1} \tilde{P}_{i}-P_{i}^{\prime} H_{i}^{-1} P_{i}\right)\right)^{-1}
\end{gathered}
$$

\subsubsection{Gibbs Sampler}

Para se obter um sorteio da posterior (23) é necessário sortear $\left\{b_{1}^{s}, \ldots, b_{m}^{s}\right\}$ da distribuição (24) e depois, condicional a $\left\{b_{1}^{s}, \ldots, b_{m_{i}}^{s}\right\}$, sortear $\left\{g_{1}^{s}, \ldots, g_{k}^{s}\right\}$ da distribuição (25). Contudo, quando o sistema é sobre identificado, a distribuição (24) não é convencional. Para simular esse sorteio, será utilizado o Gibbs sampler desenvolvido em Waggoner e Zha (2003). Como mostram os autores, essa técnica é melhor do que o importance-sampling proposto por Leeper et al (1996) e Zha (1999), que pode ser proibitivamente ineficiente para modelos com alto grau de simultaneidade.

Pode ser provado ${ }^{13}$ que o vetor aleatório $b_{i_{*}}$, condicional a $b_{1}, \ldots, b_{i_{*-1}}, b_{i_{*+1}}, \ldots, b_{m}$ é uma função linear de $q_{i_{*}}$ variáveis aleatórias $\beta_{j}$ tal que:

\footnotetext{
${ }^{13}$ A prova está em Waggoner e Zha (2003), apêndice A.
} 
(i) função densidade de $\beta_{1}$ é proporcional a $\left|\beta_{1}\right|^{T} \exp \left(-T \frac{\beta_{1}^{2}}{2}\right)$;

(ii) para $2 \leqslant j \leqslant q_{i_{*}}, \beta_{j} \sim N\left(0, \frac{1}{T}\right)$.

Seja $w$ é um vetor não nulo $m \times 1$ perpendicular a todos os vetores $\left\{U_{i} b_{i} \mid i \neq i_{*}\right\}$ e $w_{1}=$ $T_{i_{*}}^{\prime} U_{i_{*}}^{\prime} w /\left\|T_{i_{*}}^{\prime} U_{i_{*}}^{\prime} w\right\|$, onde $T_{i_{*}}$ é uma matriz $q_{i_{*}} \times q_{i_{*}}$ tal que $T_{i_{*}} T_{i_{*}}^{\prime}=S_{i_{*}}$. Escolha $\left\{w_{2}, \ldots, w_{q_{i}}\right\}^{14}$ tal que $\left\{w_{1}, w_{2}, \ldots, w_{q_{i}}\right\}$ formem uma base ortonormal para $R^{q_{1_{*}}}$. Como $b_{i_{*}} \in R^{q_{1 *}}, b_{i_{*}}$ pode ser escrito como

$$
b_{i_{*}}=T_{i_{*}} \sum_{j=1}^{q_{i_{*}}} \beta_{j} w_{j}
$$

Baseado no teorema acima, o algoritmo proposto funciona da seguinte forma:

1. Escolha valores iniciais $\left\{b_{1}^{(0)}, \ldots, b_{m}^{(0)}\right\}$, normalmente o pico da distribuição posterior.

2. $b_{i *}=b_{1}$ : Para $s=1, \ldots, N_{1}+N_{2}$ e dado $\left\{b_{2}^{(s-1)}, \ldots, b_{m}^{(s-1)}\right\}$, construa $\left\{w_{1}, w_{2}, \ldots, w_{q_{1}}\right\}$, obtenha $\beta_{1}$ da distribuição $p\left(\beta_{1}\right) \propto\left|\beta_{1}\right|^{T} \exp \left(-T \frac{\beta_{1}^{2}}{2}\right){ }^{15}$, obtenha $\left\{\beta_{2}, \ldots, \beta_{q_{1}}\right\}$ de uma distribuição Normal com média zero e variância $\frac{1}{T}$, e monte $b_{1}^{(s)}$ a partir de (26).

3. $b_{i *}=b_{2}$ : Para $s=1, \ldots, N_{1}+N_{2}$ e dado $\left\{b_{1}^{(s)}, \ldots, b_{m}^{(s-1)}\right\}$, construa $\left\{w_{1}, w_{2}, \ldots, w_{q_{2}}\right\}$, obtenha $\beta_{1}$ da distribuição $p\left(\beta_{1}\right) \propto\left|\beta_{1}\right|^{T} \exp \left(-T \frac{\beta_{1}^{2}}{2}\right)$, obtenha $\left\{\beta_{2}, \ldots, \beta_{q_{2}}\right\}$ de uma distribuição Normal com média zero e variância $\frac{1}{T}$, e monte $b_{2}^{(s)}$ a partir de (26).

4. $b_{i *}=b_{m}$ : Para $s=1, \ldots, N_{1}+N_{2}$ e dado $\left\{b_{1}^{(s)}, \ldots, b_{m-1}^{(s)}\right\}$, construa $\left\{w_{1}, w_{2}, \ldots, w_{q_{m}}\right\}$, obtenha $\beta_{1}$ da distribuição $p\left(\beta_{1}\right) \propto\left|\beta_{1}\right|^{T} \exp \left(-T \frac{\beta_{1}^{2}}{2}\right)$, obtenha $\left\{\beta_{2}, \ldots, \beta_{q_{m}}\right\}$ de uma distribuição Normal com média zero e variância $\frac{1}{T}$, e monte $b_{m}^{(s)}$ a partir de (26).

\footnotetext{
${ }^{14}$ Para ver como construir $\left\{w_{1}, w_{2}, \ldots, w_{q_{i}}\right\}$ consultar Waggoner e Zha (2003, p.357).

${ }^{15}$ Para simular esse sorteio é necessário sortear um vetor $z=\left(z_{1}, \ldots, z_{k+1}\right)^{\prime}$ i.i.d. de uma distribuição Normal com média zero e variância $\frac{1}{T}$, construir $r=z^{\prime} z$ e então obter $x= \pm \sqrt{r}$, onde $x$ pode assumir valores positivos ou negativos com igual probabilidade (WAGGONER; ZHA, 2003).
} 
5. Da sequência $\left\{b_{1}^{(0)}, \ldots, b_{m}^{(0)}, \ldots, b_{1}^{\left(N_{1}+N_{2}\right)}, \ldots, b_{m}^{\left(N_{1}+N_{2}\right)}\right\}$, mantenha apenas os últimos $N_{2}$ valores, para que os valores iniciais não interfiram no resultado.

Para os resultados apresentados abaixo foram utilizadas 30.000 repetições, das quais as 10.000 primeiras foram descartadas.

\subsection{Base de dados: Primeira etapa}

Os dados utilizados na estimação do SVAR Bayesiano e das funções de impulso resposta apresentam frequência mensal e cobrem o período de janeiro de 1996 até junho de 2013, para todas as 27 Unidades Federativas brasileiras.

Como proxy para a atividade estadual, serão utilizados os dados do CAGED de saldo de novos empregos criados. Apesar de limitar a análise ao setor formal da economia, a utilização dos dados do CAGED permite trabalhar com todas as Unidades Federativas do país, além de se obter uma amostra maior, dado sua frequência mensal. A escolha da variável de emprego em detrimento, por exemplo, da variável estadual de produção industrial, também mostra-se mais adequada para a realização da segunda etapa deste trabalho. Ao construir um indicador de sensibilidade com base na função impulso resposta obtida a partir da produção industrial estadual, estaríamos enviesando as estimações a favor dos canais de transmissão mais ativos nesse setor da economia.

Para o nível de atividade agregado, será utilizada a série de produção industrial da Pesquisa Industrial Mensal do IBGE $^{16}$. O comportamento da inflação será capturado pelo Índice Geral de Preços - Disponibilidade Interna (IGP-DI). Como será discutido mais adiante, a escolha por esse índice de inflação em detrimento ao IPCA deve-se ao fato do IGP-DI reduzir o fenômeno conhecido como price puzzle.

A taxa de juros Selic - acumulada no mês e anualizada - será utilizada como instrumento de política monetária. Por fim, para melhor caracterizar o mercado monetário, será utilizada a série de meios de pagamento (M1) - média nos dias úteis do mês - deflacionada para o nível de preços de janeiro de 1996.

\footnotetext{
${ }^{16}$ Originalmente, essa série utiliza o valor da média de 2002 como base igual a 100. Alteramos a série para utilizar o valor de janeiro de 1996 como base.
} 
Figura 1: Variáveis
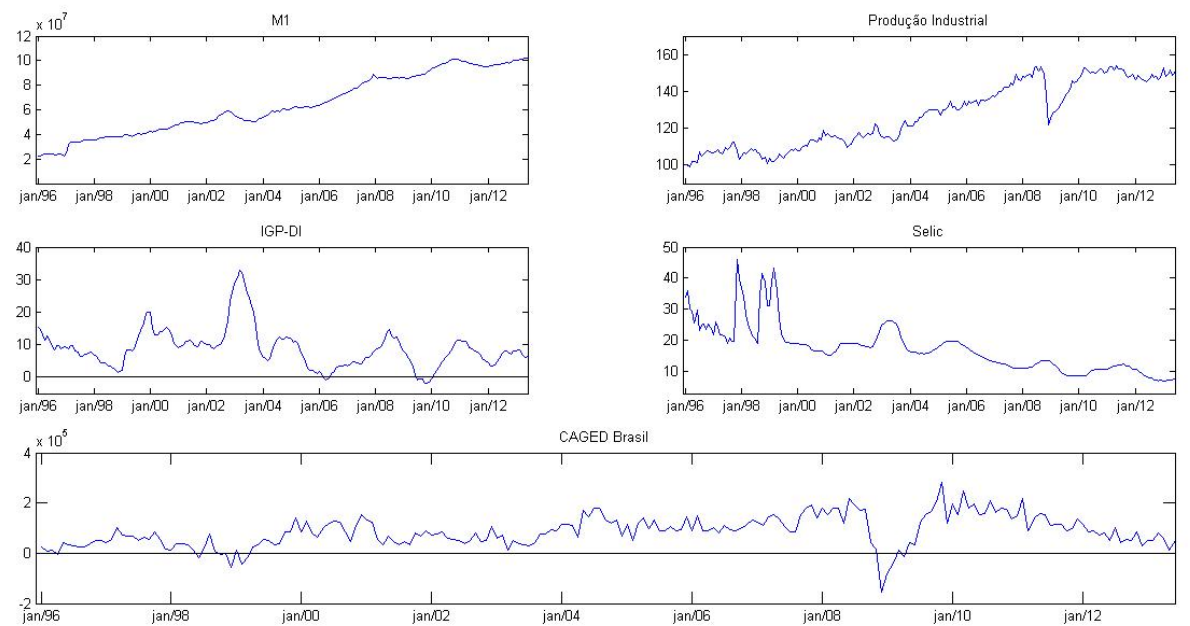

As séries de produção industrial, meios de pagamento e as séries de saldo de novos empregos formais criados por Unidade Federativa do CAGED foram dessazonalizadas. Adicionalmente, séries compostas por taxas ou proporções serão utilizadas em pontos percentuais. Já as séries de produção industrial e meios de pagamento estão em logaritmo (multiplicado por 100). Por fim, as séries de emprego estadual serão utilizadas no nível.

As variáveis foram incluídas no vetor autorregressivo com a seguinte ordenação:

$$
y_{t}=\left[y_{1, t}, \ldots, y_{27, t}, \text { ind }_{t}, \pi_{t}, r_{t}, m 1_{t}\right]^{\prime}
$$

onde $y_{i, t}, i=1, \ldots, 27$, corresponde às 27 variáveis regionais, $i n d_{t}$ representa o logaritmo multiplicado por 100 - da produção industrial nacional, $\pi_{t}$ a taxa de inflação, $r_{t}$ a taxa de juros Selic e $m 1_{t}$ o logaritmo do agregado monetário, também multiplicado por 100 . As variáveis não transformadas se encontram na figura 1.

\subsection{Resultados: SVAR Bayesiano ${ }^{17}$}

Para as variáveis agregadas, as respostas a um choque de política monetária encontradas a partir do SVAR Bayesiano podem ser observadas na figura 2. O intervalo de confiança Bayesiano de $68 \%$ é normalmente reportado, uma vez que bandas de $90 \%$ ou $95 \%$

\footnotetext{
${ }^{17}$ O SVAR Bayesiano foi estimado a partir do software Matlab, com um código baseado em Waggoner e Zha (2003), disponível em http://www.tzha.net/code.
} 
Figura 2: Resposta das Variáveis Agregadas a um Choque na Selic
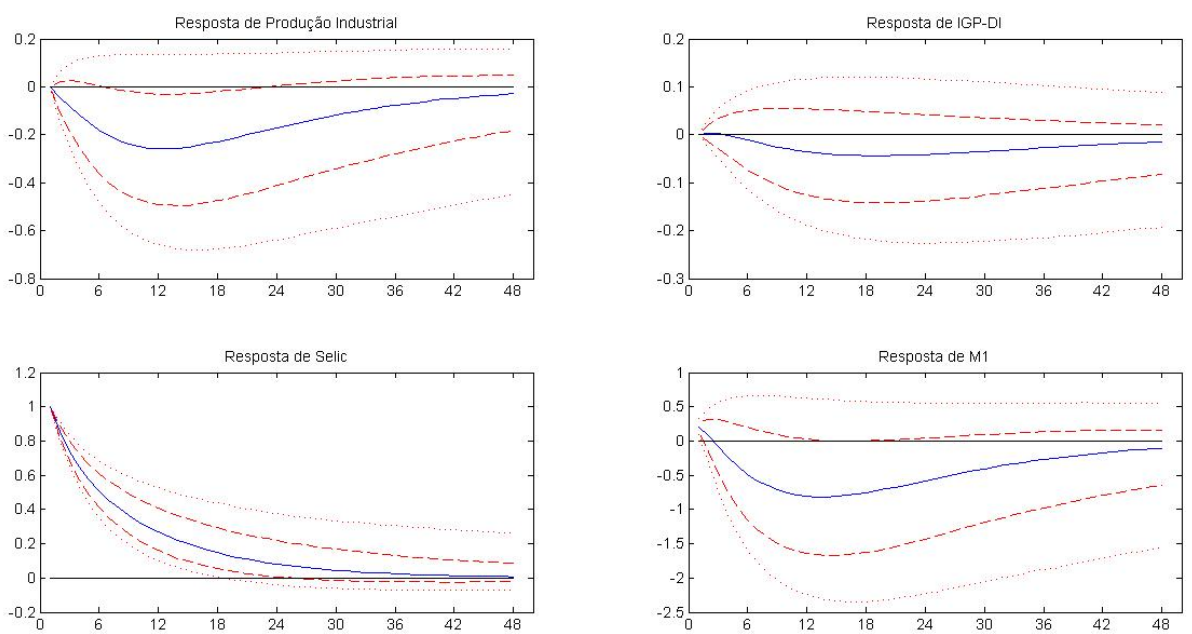

Nota: As linhas azul sólida, vermelha tracejada, e vermelha pontilhada indicam, respectivamente, a mediana, o intervalo de credibilidade de $68 \%$ e o intervalo de credibilidade de $90 \%$ da função impulso resposta.

Tabela 2: $P\left(F I R_{t}<0 \mid\right)$

\begin{tabular}{ccccc}
\hline Meses & Prod. Industrial & IGP-DI & Selic & M1 \\
\hline \hline 4 & $80 \%$ & $51 \%$ & $0 \%$ & $68 \%$ \\
8 & $85 \%$ & $61 \%$ & $0 \%$ & $80 \%$ \\
12 & $87 \%$ & $66 \%$ & $0 \%$ & $83 \%$ \\
16 & $87 \%$ & $68 \%$ & $2 \%$ & $84 \%$ \\
20 & $85 \%$ & $69 \%$ & $7 \%$ & $84 \%$ \\
24 & $83 \%$ & $70 \%$ & $14 \%$ & $82 \%$ \\
28 & $81 \%$ & $70 \%$ & $20 \%$ & $80 \%$ \\
32 & $78 \%$ & $70 \%$ & $25 \%$ & $78 \%$ \\
36 & $75 \%$ & $70 \%$ & $30 \%$ & $75 \%$ \\
40 & $72 \%$ & $70 \%$ & $34 \%$ & $72 \%$ \\
44 & $69 \%$ & $69 \%$ & $36 \%$ & $69 \%$ \\
48 & $67 \%$ & $69 \%$ & $39 \%$ & $67 \%$ \\
\hline
\end{tabular}

podem levar a conclusões erradas quando a distribuição da função impulso resposta for assimétrica devido a não linearidades (BLAKE; MUMTAZ, 2012). Na tabela 2 é possível observar a probabilidade de a resposta ao choque de política monetária ser menor do que zero para alguns meses selecionados.

Os resultados são consistentes com o encontrado para o Brasil (MINELLA, 2003; CÉSPEDES et al, 2008; ARQUETE; JÚNIOR, 2003). Após um choque contracionista de 1 p.p., a taxa Selic cai de forma consistente até convergir de volta para o seu valor inicial. A função impulso resposta para a taxa Selic é a que apresenta menor grau de incerteza, uma vez que sua posterior é bastante concentrada ao redor da mediana. O intervalo de 
credibilidade de $90 \%$ contém o valor zero apenas 18 meses após o choque, indicando que a Selic converge de forma lenta para seu valor de estado estacionário.

O choque positivo na taxa de juros tem um impacto negativo na atividade, cuja resposta ao choque de política monetária apresenta formato hump-shaped. A produção industrial se contrai por 11 meses seguidos, até alcançar a redução mínima de -0.26 p.p do seu valor de estado estacionário. Depois desse período, volta a crescer, convergindo para o seu valor original. Apesar da incerteza considerável com relação ao sinal da resposta da atividade a um choque monetário, sua posterior é bastante concentrada em valores negativos, sendo que o intervalo de credibilidade de $68 \%$ não contém o zero do $6^{\circ}$ ao $21^{\circ}$ mês após a elevação na Selic.

Contemporaneamente ao choque exógeno na taxa Selic, o M1 apresenta uma leve expansão, mas começa a se contrair logo no mês seguinte. Os meios de pagamento apresentam contração máxima 12 meses após o choque, quando atingem um montante 1,96 p.p. menor do que seu valor de estado estacionário. Com exceção do mês no qual o choque ocorre, a posterior da resposta do M1 também é mais concentrada em valores negativos do espaço paramétrico.

Por fim, antes de detalhar os resultados obtidos para a inflação, é necessário comentar alguns pontos sobre o índice de preços utilizado. Desde junho de 1999, a política monetária no Brasil é conduzida de acordo com o sistema de metas de inflação, no qual o Banco Central tem como objetivo manter a taxa de variação de preços no centro da meta estabelecida. Dentro desse sistema, o índice de preços oficial é o Índice de Preços ao Consumidor Amplo (IPCA), tornando-o o candidato natural para integrar o vetor de variáveis do modelo BVAR e compor a regra de política monetária.

Contudo, para o modelo com IPCA, a taxa de inflação responde positivamente a um choque de política monetária. Esse resultado, conhecido como inflation-rate puzzle ${ }^{18}$, é recorrente na literatura, tanto para economias da OCDE como para o Brasil (MINELLA, 2003; CÉSPEDES et al, 2008; SIMS, 1992).

Existem algumas possíveis explicações para esse comportamento da inflação. Segundo Sims (1992), o price puzzle pode decorrer da omissão de variáveis relevantes do conjunto

\footnotetext{
${ }^{18}$ Para modelos que se utilizam do nível de preços no lugar da taxa de inflação, esse fenômeno é denominado price puzzle.
} 
Figura 3: IPCA e IGP-DI

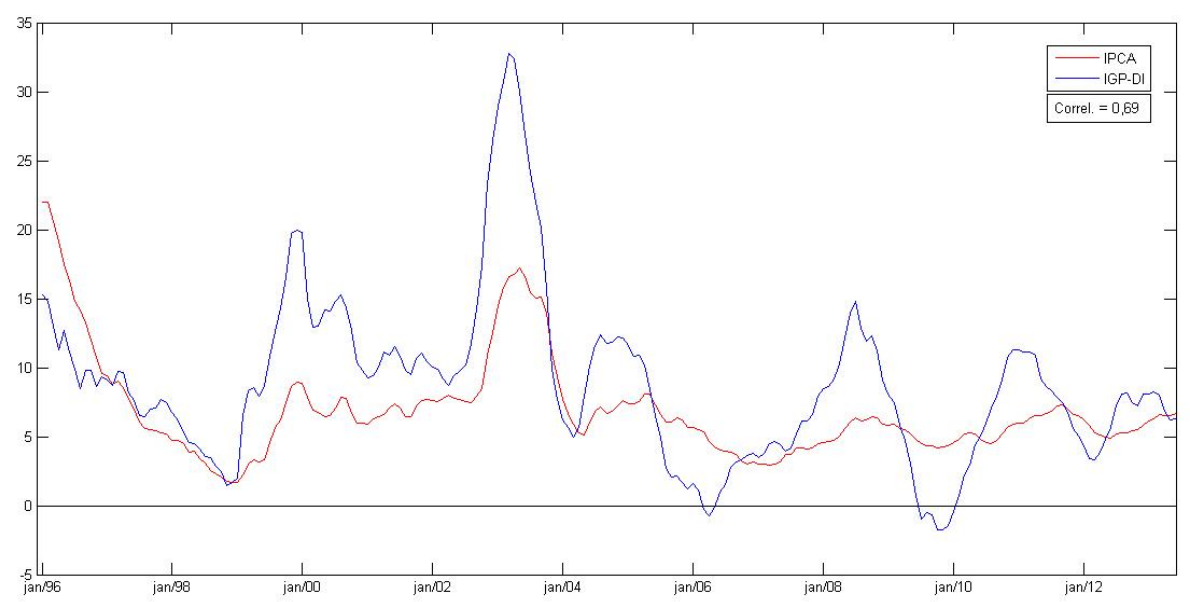

de informação da autoridade monetária. Se o Banco Central levar em consideração a expectativa de inflação dos agentes, sendo que esta não foi incluída no modelo empírico, mudanças na taxa de juros provenientes de respostas sistêmicas a essas variáveis serão interpretadas como choques de política monetária. Como parte das expectativas realmente se realizaram como inflação ao longo do tempo, o modelo pode, erroneamente, indicar que um choque monetário exógeno acarreta elevação da inflação. Para solucionar o price puzzle, Sims (1992) sugere a inclusão de variáveis sensíveis às expectativas de inflação, como a série de preços de commodities.

Para o modelo em questão, optou-se por substituir o IPCA pelo IGP-DI. Como é possível observar na figura 3, as duas séries apresentam alta correlação, de maneira que parte significativa da informação contida no IPCA também está contida no IGP-DI. Adicionalmente, o IGP-DI mostra-se mais sensível aos preços de commodities, já que, além de um componente de preços ao consumidor, o índice também é composto por preços de atacado.

Na figura 4 é possível comparar a mediana da posterior da resposta da inflação ao choque de política monetária, para os dois índices de preços diferentes. Como é possível observar, a substituição do IPCA pelo IGP-DI de fato reduziu consideravelmente o price puzzle, tanto em sua magnitude, como em sua duração.

O fato dessa mudança não eliminar por completo o price puzzle pode indicar que parte desse comportamento não advém da omissão de variáveis relevantes, mas sim da presença 
Figura 4: Resposta do IPCA e IGP-DI

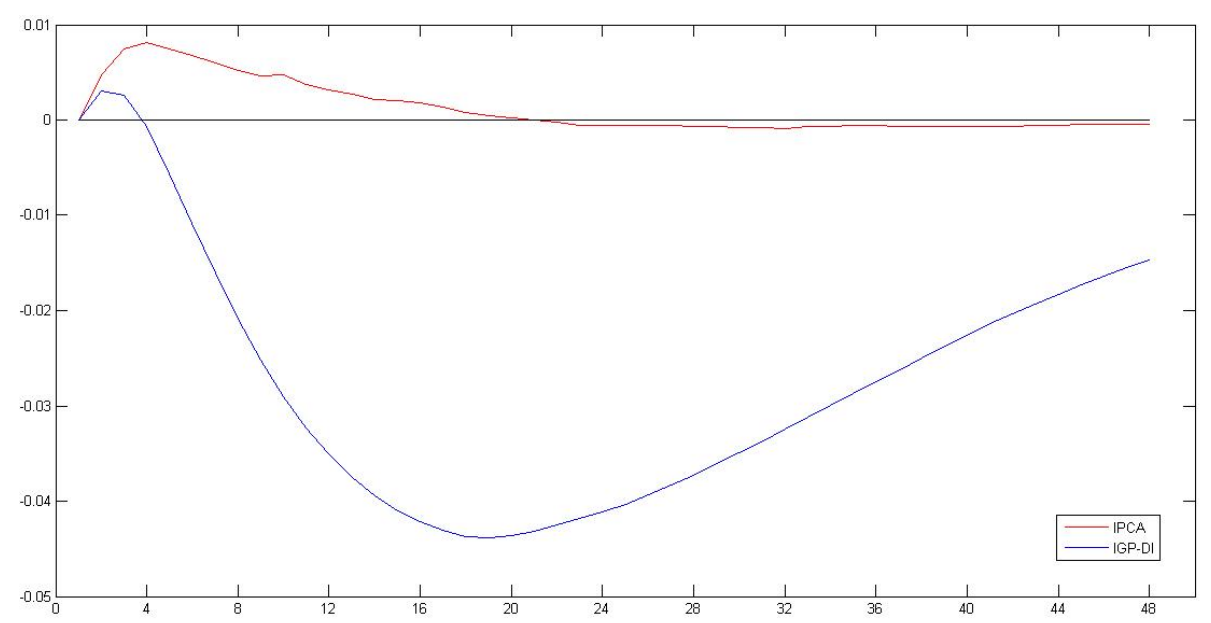

do canal de custos na transmissão da política monetária. Segundo Barth III e Ramey (2001), caso as firmas remunerem seus fatores de produção antes de receber a receita proveniente de suas vendas, podem recorrer a empréstimos de curto prazo para financiar esses pagamentos. Dessa forma, um choque monetário contracionista elevaria os custos de produção, elevando os preços.

Com exceção da inflação, a troca do IPCA pelo IGP-DI resultou em posteriors para as funções impulso resposta bastante similares. Tanto a mediana, quanto a caracterização das incertezas dessas funções permaneceram qualitativamente iguais, de forma que optou-se pela utilização do IGP-DI.

A resposta da taxa de inflação é positiva para os dois primeiros meses após o choque de política monetária, nos quais a mesma aumenta 0,003 p.p. em relação ao seu nível de estado estacionário. A partir do $3^{\circ}$ mês ela já reduz-se para um patamar inferior ao seu valor original, atingindo seu valor mínimo 18 meses após o choque nos juros, período no qual ela se encontra 0.04 p.p. menor do que o seu valor inicial. De todas as variáveis agregadas, a taxa de inflação é a que apresenta maior incerteza em relação ao sinal de sua resposta, sendo que tanto o intervalo de credibilidade de $68 \%$, como o de $90 \%$, contêm o zero para qualquer horizonte de tempo.

As funções de impulso resposta das variáveis regionais encontram-se na figura 5. Cada ponto do gráfico representa o número de empregos criados a cada instante do tempo, após um choque positivo de 1 p.p. na taxa de juros em $t=1$. 
Para permitir a comparação entre as Unidades Federativas, a função impulso resposta estadual foi dividida pelo seu valor de estado estacionário ${ }^{19}$. A opção ideal para se comparar as respostas entre Estados seria dividir cada função de impulso resposta sorteada por seu respectivo equilíbrio de estado estacionário, obtendo a distribuição das respostas ponderadas. Contudo, nem todos os sorteios correspondem a um sistema de equações em diferenças convergente, uma vez que possuem autovalores fora do círculo unitário. A solução encontrada consiste em dividir a mediana das funções de impulso resposta pelo valor de estado estacionário obtido a partir da mediana dos parâmetros do SVAR, uma vez que os mesmos possuem solução convergente.

Os resultados ponderados estão nas tabelas 4 a 8 . A tabela 3 apresenta a resposta ponderada de cada UF, acumulada pelo período de 48 meses. Os resultados foram construídos dividindo a soma total de postos de trabalho criados ao longo do período pelo valor de estado estacionário multiplicado por 48. Para isso foi utilizada a mediana da função impulso resposta. Dessa forma, os valores na primeira coluna podem ser interpretados como a porcentagem de empregos criados além ou aquém do que teria sido obtido caso a economia estivesse no equilíbrio de estado estacionário.

Na última coluna da tabela 3, as Unidades Federativas foram ordenadas de acordo com suas respectivas respostas relativas acumuladas. O Estado com valor mais negativo foi ranqueado em primeiro, e assim por diante. Observe que essa medida não é exatamente uma medida de sensibilidade, uma vez que Estados com respostas grandes, mas positivas, aparecerão nas últimas colocações.

As tabelas 4 e 5 apresentam as mesmas informações que a tabela 3, porém levando em consideração a incerteza presente na posterior de cada função de impulso resposta. Os resultados ponderados foram construídos da mesma maneira descrita acima. Contudo, a resposta do emprego é considerada nula para os instantes de tempo em que o zero estiver contido no intervalo de credibilidade de $68 \%$. A tabela 5 segue a mesma lógica, porém se utilizando do intervalo de credibilidade de $90 \%$.

Como é possível observar, a reação das Unidades Federativas é bastante heterogênea, tanto em relação à magnitude e timing, como em relação ao sinal e a caracterização da

\footnotetext{
${ }^{19}$ Substituindo $y_{t}=y_{t-1}=\ldots=y_{t-p}=y_{s s} \mathrm{em}$ (4) é fácil ver que $y_{s s}=\left(I_{n}-\sum_{l=1}^{p} B_{l}^{\prime}\right)^{-1} c$, onde $y_{s s}$ é o valor do vetor $y$ no estado estacionário.
} 
Figura 5: Resposta das Variáveis Regionais a um Choque na Selic
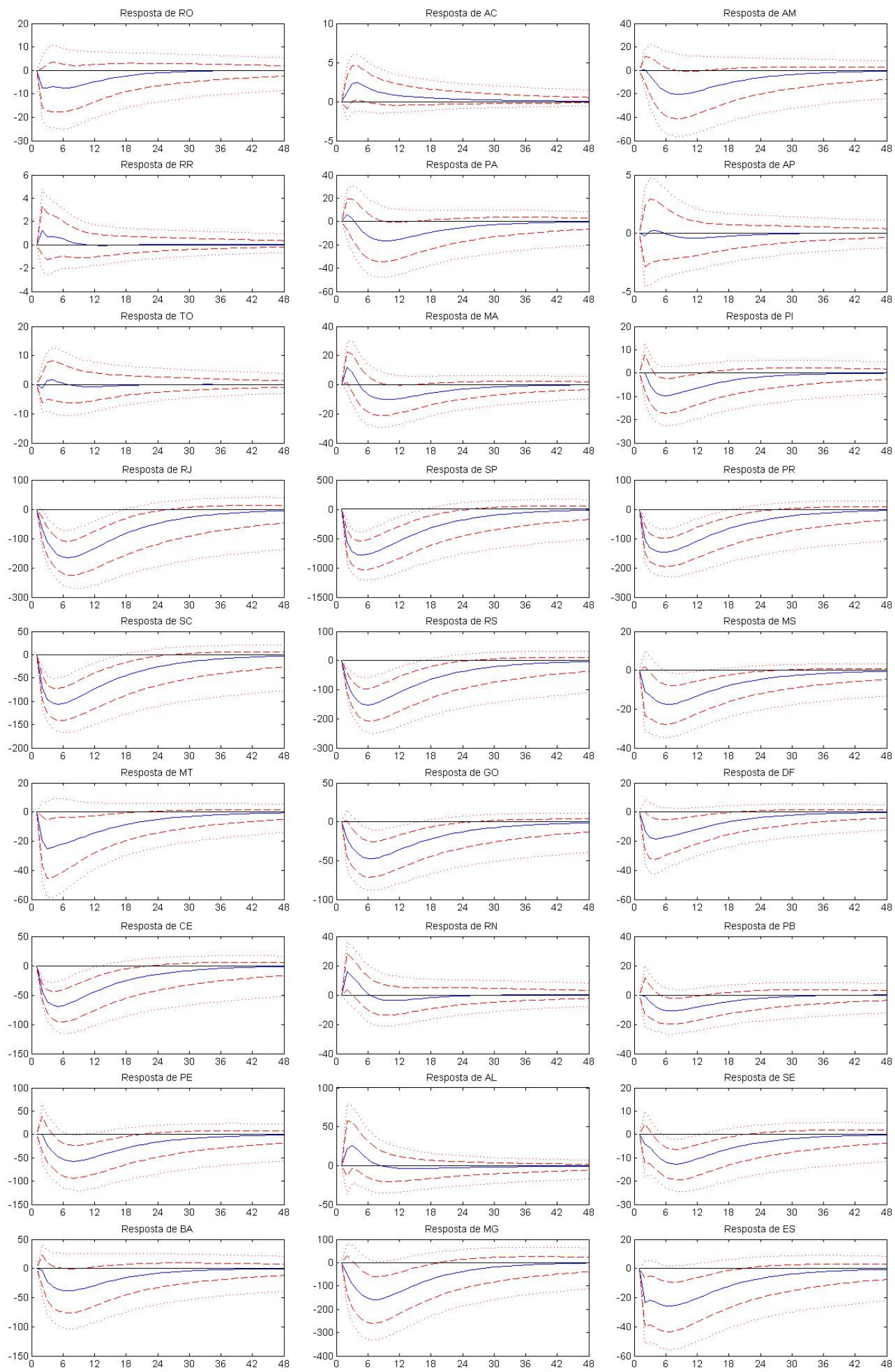

Nota: As linhas azul sólida, vermelha tracejada, e vermelha pontilhada indicam, respectivamente, a mediana, o intervalo de credibilidade de $68 \%$ e o intervalo de credibilidade de $90 \%$ da função impulso resposta. 
incerteza presentes nas respostas. Para facilitar a análise dos resultados, as Unidades Federativas serão divididas em três grupos de nove unidades cada, baseados na magnitude de suas respectivas respostas relativas acumuladas.

O primeiro grupo consiste nas unidades mais sensíveis à inovação de política monetária. O primeiro padrão identificável a partir da tabela 3 é a concentração regional desses Estados: das sete unidades que compõem as regiões Sul e Sudeste, quatro aparecem entre os mais sensíveis. Dentre eles, São Paulo é o Estado que perde mais empregos em relação ao seu potencial de estado estacionário, criando um total de postos de trabalho $0.92 \%$ menor do que teria sido alcançado caso o choque não tivesse ocorrido. Por outro lado, dos 16 Estados que compõem as regiões Norte e Nordeste, apenas 3 aparecem no grupo dos mais sensíveis à política monetária, sendo eles os Estados do Amazonas, Ceará e Pernambuco. O fato de o Estado do Amazonas apresentar um comportamento tão distinto das outras unidades da região Norte pode estar relacionado com a importância da Zona Franca de Manaus para a economia do Estado.

Quanto à incerteza presente na posterior das funções impulso resposta estaduais, também é possível identificar alguns padrões característicos do grupo de Estados mais sensíveis à política monetária. Na sua grande maioria, esses Estados são os que apresentam o menor grau de incerteza quanto ao sinal e o formato da resposta, com posterior concentrada em valores negativos e com formato hump-shaped. Com exceção de Pernambuco e Amazonas, conforme levamos em conta intervalos de credibilidade maiores, os resultados não só continuam válidos, como esses Estados continuam entre os mais sensíveis ao choque de política monetária.

O segundo grupo analisado contém aquelas Unidades Federativas que apresentam sensibilidade intermediária ao choque de política monetária. O padrão regional dessas unidades é um pouco mais disperso, com unidades das regiões Sudeste, Centro-Oeste e Nordeste. Apenas as regiões Sul e Norte não apresentam nenhuma UF no grupo intermediário.

Quanto ao formato da posterior das funções de impulso resposta, é possível perceber uma maior incerteza quanto ao sinal da resposta. Apesar da posterior ainda ser bastante concentrada nos valores negativos do espaço paramétrico, quase todas as Unidades Federativas passam a ter resposta nula quando o intervalo de credibilidade é levado em 
consideração. Adicionalmente, alguns Estados desse grupo apresentam funções de impulso resposta menos comportadas, com valores positivos para os primeiros períodos de tempo após o choque.

Por fim, os nove Estados restantes compõem o grupo dos menos sensíveis à política monetária, ou ainda daquelas Unidades Federativas que apresentaram resposta acumulada positiva. Esse grupo apresenta um padrão regional bastante claro, com forte concentração nas regiões Norte e Nordeste, com destaque para a primeira.

A posterior das funções de impulso resposta apresentam maior grau de incerteza, não apenas em relação ao sinal da resposta, como também em relação ao seu formato. É possível observar que, para alguns Estados, a mediana da função impulso resposta é positiva por um longo período de tempo, e os percentis mais baixos apresentam formato diferente dos percentis mais altos. Ambos intervalos de credibilidade contêm o zero em quase todos os períodos de tempo.

Na tabela 6 encontram-se as respostas relativas acumuladas máximas de cada unidade federativa. Para cada instante de tempo o número de postos de trabalho criados foi acumulado e dividido por seu valor de longo prazo multiplicado pela quantidade de meses em questão. Esse processo foi repetido até se obter o valor máximo para cada Estado. Observe que o mês no qual a resposta acumulada máxima ocorre é diferente do mês onde a resposta máxima ocorre.

É possível observar que a ordenação obtida pela resposta relativa acumulada em 48 meses e pela resposta relativa acumulada máxima são bastante parecidas. Apesar de mudanças na posição de alguns Estados, são raros os casos onde houve mudança entre os três grupos descritos acima.

Na média, a resposta relativa acumulada máxima ocorre após 10 meses da incidência do choque de política monetária. Nenhum padrão claro emerge da análise dos dados apresentados na tabela 6. Os Estados das regiões Sul, Sudeste e Centro-Oeste são mais homogêneos quanto ao timing da resposta máxima acumulada. Já os Estados das regiões Norte de Nordeste apresentam uma variância maior, com Estados que respondem muito rápido e outros muito lentamente. Contudo, na média todos os grupos são bastante similares. 
Tabela 3: Resposta Acumulada Após 48 Meses

\begin{tabular}{|c|c|c|c|c|}
\hline UF & $\begin{array}{c}\text { Resposta } \\
\text { Acumulada }\end{array}$ & Emprego & $\begin{array}{c}\text { Estado } \\
\text { Estacionário }\end{array}$ & Posição \\
\hline \multicolumn{5}{|c|}{ Norte } \\
\hline Rondônia & $-0,37 \%$ & -110 & 621 & 19 \\
\hline Acre & $0,66 \%$ & 25 & 79 & 27 \\
\hline Amazonas & $-0,73 \%$ & -353 & 1.002 & 4 \\
\hline Roraima & $0,18 \%$ & 5 & 63 & 26 \\
\hline Pará & $-0,34 \%$ & -262 & 1.627 & 20 \\
\hline Amapá & $-0,07 \%$ & -5 & 160 & 22 \\
\hline Tocantins & $0,00 \%$ & 0 & 220 & 23 \\
\hline \multicolumn{5}{|c|}{ Nordeste } \\
\hline Maranhão & $-0,40 \%$ & -138 & 721 & 16 \\
\hline Piauí & $-0,43 \%$ & -134 & 649 & 15 \\
\hline Ceará & $-0,73 \%$ & -1.082 & 3.094 & 5 \\
\hline Rio Grande do Norte & $0,01 \%$ & 4 & 1.042 & 24 \\
\hline Paraíba & $-0,38 \%$ & -159 & 862 & 18 \\
\hline Pernambuco & $-0,65 \%$ & -971 & 3.099 & 8 \\
\hline Alagoas & $0,07 \%$ & 10 & 296 & 25 \\
\hline Sergipe & $-0,62 \%$ & -214 & 720 & 10 \\
\hline Bahia & $-0,33 \%$ & -589 & 3.698 & 21 \\
\hline \multicolumn{5}{|c|}{ Sudeste } \\
\hline Minas Gerais & $-0,51 \%$ & -2.586 & 10.537 & 13 \\
\hline Espírito Santo & $-0,47 \%$ & -466 & 2.065 & 14 \\
\hline Rio de Janeiro & $-0,72 \%$ & -2.978 & 8.634 & 7 \\
\hline São Paulo & $-0,92 \%$ & -12.935 & 29.197 & 1 \\
\hline \multicolumn{5}{|c|}{ Sul } \\
\hline Paraná & $-0,79 \%$ & -2.596 & 6.880 & 3 \\
\hline Santa Catarina & $-0,73 \%$ & -1.787 & 5.121 & 6 \\
\hline Rio Grande do Sul & $-0,83 \%$ & -2.533 & 6.391 & 2 \\
\hline \multicolumn{5}{|c|}{ Centro-Oeste } \\
\hline Mato Grosso do Sul & $-0,63 \%$ & -308 & 1.022 & 9 \\
\hline Mato Grosso & $-0,59 \%$ & -372 & 1.315 & 11 \\
\hline Goiás & $-0,56 \%$ & -830 & 3.104 & 12 \\
\hline Distrito Federal & $-0,39 \%$ & -282 & 1.525 & 17 \\
\hline
\end{tabular}


Tabela 4: Resposta Acumulada Após 48 Meses - 68\% I.C.

\begin{tabular}{|c|c|c|c|c|}
\hline UF & $\begin{array}{c}\text { Resposta } \\
\text { Acumulada }\end{array}$ & Emprego & $\begin{array}{c}\text { Estado } \\
\text { Estacionário }\end{array}$ & Posição \\
\hline \multicolumn{5}{|c|}{ Norte } \\
\hline Rondônia & $0,00 \%$ & 0 & 621 & 21 \\
\hline Acre & $0,18 \%$ & 7 & 79 & 23 \\
\hline Amazonas & $-0,24 \%$ & -114 & 1.002 & 16 \\
\hline Roraima & $0,00 \%$ & 0 & 63 & 21 \\
\hline Pará & $-0,08 \%$ & -62 & 1.627 & 18 \\
\hline Amapá & $0,00 \%$ & 0 & 160 & 21 \\
\hline Tocantins & $0,00 \%$ & 0 & 220 & 21 \\
\hline \multicolumn{5}{|c|}{ Nordeste } \\
\hline Maranhão & $-0,07 \%$ & -24 & 721 & 19 \\
\hline Piauí & $-0,24 \%$ & -76 & 649 & 15 \\
\hline Ceará & $-0,62 \%$ & -919 & 3.094 & 6 \\
\hline Rio Grande do Norte & $0,06 \%$ & 29 & 1.042 & 22 \\
\hline Paraíba & $-0,21 \%$ & -86 & 862 & 17 \\
\hline Pernambuco & $-0,47 \%$ & -697 & 3.099 & 11 \\
\hline Alagoas & $0,00 \%$ & 0 & 296 & 21 \\
\hline Sergipe & $-0,48 \%$ & -165 & 720 & 8 \\
\hline Bahia & $-0,06 \%$ & -114 & 3.698 & 20 \\
\hline \multicolumn{5}{|c|}{ Sudeste } \\
\hline Minas Gerais & $-0,38 \%$ & -1.912 & 10.537 & 12 \\
\hline Espírito Santo & $-0,38 \%$ & -373 & 2.065 & 13 \\
\hline Rio de Janeiro & $-0,63 \%$ & -2.620 & 8.634 & 5 \\
\hline São Paulo & $-0,82 \%$ & -11.476 & 29.197 & 1 \\
\hline \multicolumn{5}{|c|}{ Sul } \\
\hline Paraná & $-0,70 \%$ & -2.328 & 6.880 & 3 \\
\hline Santa Catarina & $-0,65 \%$ & -1.587 & 5.121 & 4 \\
\hline Rio Grande do Sul & $-0,73 \%$ & -2.228 & 6.391 & 2 \\
\hline \multicolumn{5}{|c|}{ Centro-Oeste } \\
\hline Mato Grosso do Sul & $-0,54 \%$ & -264 & 1.022 & 7 \\
\hline Mato Grosso & $-0,48 \%$ & -300 & 1.315 & 9 \\
\hline Goiás & $-0,48 \%$ & -708 & 3.104 & 10 \\
\hline Distrito Federal & $-0,29 \%$ & -213 & 1.525 & 14 \\
\hline
\end{tabular}


Tabela 5: Resposta Acumulada Após 48 Meses - 90 \% I.C.

\begin{tabular}{|c|c|c|c|c|}
\hline UF & $\begin{array}{c}\text { Resposta } \\
\text { Acumulada }\end{array}$ & Emprego & $\begin{array}{c}\text { Estado } \\
\text { Estacionário }\end{array}$ & Posição \\
\hline \multicolumn{5}{|c|}{ Norte } \\
\hline Rondônia & $0,00 \%$ & 0 & 621 & 11 \\
\hline Acre & $0,00 \%$ & 0 & 79 & 11 \\
\hline Amazonas & $0,00 \%$ & 0 & 1.002 & 11 \\
\hline Roraima & $0,00 \%$ & 0 & 63 & 11 \\
\hline Pará & $0,00 \%$ & 0 & 1.627 & 11 \\
\hline Amapá & $0,00 \%$ & 0 & 160 & 11 \\
\hline Tocantins & $0,00 \%$ & 0 & 220 & 11 \\
\hline \multicolumn{5}{|c|}{ Nordeste } \\
\hline Maranhão & $0,00 \%$ & 0 & 721 & 11 \\
\hline Piauí & $0,00 \%$ & 0 & 649 & 11 \\
\hline Ceará & $-0,46 \%$ & -682 & 3.094 & 6 \\
\hline Rio Grande do Norte & $0,00 \%$ & 0 & 1.042 & 11 \\
\hline Paraíba & $0,00 \%$ & 0 & 862 & 11 \\
\hline Pernambuco & $-0,08 \%$ & -114 & 3.099 & 10 \\
\hline Alagoas & $0,00 \%$ & 0 & 296 & 11 \\
\hline Sergipe & $-0,24 \%$ & -83 & 720 & 9 \\
\hline Bahia & $0,00 \%$ & 0 & 3.698 & 11 \\
\hline \multicolumn{5}{|c|}{ Sudeste } \\
\hline Minas Gerais & $0,00 \%$ & 0 & 10.537 & 11 \\
\hline Espírito Santo & $0,00 \%$ & 0 & 2.065 & 11 \\
\hline Rio de Janeiro & $-0,49 \%$ & -2.017 & 8.634 & 5 \\
\hline São Paulo & $-0,66 \%$ & -9.236 & 29.197 & 1 \\
\hline \multicolumn{5}{|c|}{ Sul } \\
\hline Paraná & $-0,59 \%$ & -1.933 & 6.880 & 2 \\
\hline Santa Catarina & $-0,53 \%$ & -1.298 & 5.121 & 4 \\
\hline Rio Grande do Sul & $-0,58 \%$ & -1.772 & 6.391 & 3 \\
\hline \multicolumn{5}{|c|}{ Centro-Oeste } \\
\hline Mato Grosso do Sul & $-0,25 \%$ & -123 & 1.022 & 8 \\
\hline Mato Grosso & $0,00 \%$ & 0 & 1.315 & 11 \\
\hline Goiás & $-0,32 \%$ & -482 & 3.104 & 7 \\
\hline Distrito Federal & $0,00 \%$ & 0 & 1.525 & 11 \\
\hline
\end{tabular}


Tabela 6: Resposta Acumulada Máxima

\begin{tabular}{|c|c|c|c|c|c|}
\hline UF & $\begin{array}{c}\text { Máx. } \\
\text { Acumulado }\end{array}$ & Emprego & $\begin{array}{c}\text { Estado } \\
\text { Estacionário }\end{array}$ & Mês & Posição \\
\hline \multicolumn{6}{|c|}{ Norte } \\
\hline Rondônia & $-1,03 \%$ & -58 & 621 & 9 & 16 \\
\hline Acre & $2,07 \%$ & 10 & 79 & 6 & 26 \\
\hline Amazonas & $-1,41 \%$ & -211 & 1.002 & 15 & 8 \\
\hline Roraima & $1,05 \%$ & 3 & 63 & 4 & 25 \\
\hline Pará & $-0,62 \%$ & -172 & 1.627 & 17 & 20 \\
\hline Amapá & $-0,14 \%$ & -4 & 160 & 19 & 21 \\
\hline Tocantins & $0,26 \%$ & 3 & 220 & 5 & 22 \\
\hline \multicolumn{6}{|c|}{ Nordeste } \\
\hline Maranhão & $0,95 \%$ & 21 & 721 & 3 & 24 \\
\hline Piauí & $-1,03 \%$ & -74 & 649 & 11 & 15 \\
\hline Ceará & $-1,78 \%$ & -495 & 3.094 & 9 & 3 \\
\hline Rio Grande do Norte & $0,91 \%$ & 29 & 1.042 & 3 & 23 \\
\hline Paraíba & $-0,89 \%$ & -92 & 862 & 12 & 18 \\
\hline Pernambuco & $-1,31 \%$ & -570 & 3.099 & 14 & 10 \\
\hline Alagoas & $5,78 \%$ & 69 & 296 & 4 & 27 \\
\hline Sergipe & $-1,29 \%$ & -121 & 720 & 13 & 11 \\
\hline Bahia & $-0,76 \%$ & -335 & 3.698 & 12 & 19 \\
\hline \multicolumn{6}{|c|}{ Sudeste } \\
\hline Minas Gerais & $-1,13 \%$ & -1.434 & 10.537 & 12 & 13 \\
\hline Espírito Santo & $-1,06 \%$ & -240 & 2.065 & 11 & 14 \\
\hline Rio de Janeiro & $-1,50 \%$ & -1.551 & 8.634 & 12 & 6 \\
\hline São Paulo & $-2,18 \%$ & -5.726 & 29.197 & 9 & 1 \\
\hline \multicolumn{6}{|c|}{ Sul } \\
\hline Paraná & $-1,76 \%$ & -1.210 & 6.880 & 10 & 4 \\
\hline Santa Catarina & $-1,67 \%$ & -772 & 5.121 & 9 & 5 \\
\hline Rio Grande do Sul & $-1,86 \%$ & -1.189 & 6.391 & 10 & 2 \\
\hline \multicolumn{6}{|c|}{ Centro-Oeste } \\
\hline Mato Grosso do Sul & $-1,37 \%$ & -154 & 1.022 & 11 & 9 \\
\hline Mato Grosso & $-1,48 \%$ & -155 & 1.315 & 8 & 7 \\
\hline Goiás & $-1,19 \%$ & -408 & 3.104 & 11 & 12 \\
\hline Distrito Federal & $-0,95 \%$ & -131 & 1.525 & 9 & 17 \\
\hline
\end{tabular}


Por fim, a tabela 7 apresenta a resposta relativa acumulada ao longo de quatro cortes no tempo, o que permite observar se existe algum padrão na dinâmica temporal das respostas. 
Tabela 7: Resposta Acumulada - Períodos Diferentes

\begin{tabular}{|c|c|c|c|c|c|c|c|c|}
\hline \multirow{2}{*}{ UF } & \multicolumn{4}{|c|}{ Resposta Acumulada } & \multicolumn{4}{|c|}{ Posição Relativa } \\
\hline & 12 meses & 24 meses & 36 meses & 48 meses & 12 meses & 24 meses & 36 meses & 48 meses \\
\hline \multicolumn{9}{|c|}{ Norte } \\
\hline Rondônia & $-1,00 \%$ & $-0,70 \%$ & $-0,49 \%$ & $-0,37 \%$ & 16 & 17 & 19 & 19 \\
\hline Acre & $1,70 \%$ & $1,15 \%$ & $0,85 \%$ & $0,66 \%$ & 26 & 27 & 27 & 27 \\
\hline Amazonas & $-1,37 \%$ & $-1,23 \%$ & $-0,94 \%$ & $-0,73 \%$ & 8 & 6 & 5 & 4 \\
\hline Roraima & $0,57 \%$ & $0,28 \%$ & $0,21 \%$ & $0,18 \%$ & 25 & 25 & 26 & 26 \\
\hline Pará & $-0,57 \%$ & $-0,57 \%$ & $-0,43 \%$ & $-0,34 \%$ & 20 & 21 & 21 & 20 \\
\hline Amapá & $-0,10 \%$ & $-0,13 \%$ & $-0,10 \%$ & $-0,07 \%$ & 22 & 22 & 22 & 22 \\
\hline Tocantins & $0,01 \%$ & $-0,05 \%$ & $-0,02 \%$ & $0,00 \%$ & 23 & 23 & 23 & 23 \\
\hline \multicolumn{9}{|c|}{ Nordeste } \\
\hline Maranhão & $-0,53 \%$ & $-0,66 \%$ & $-0,51 \%$ & $-0,40 \%$ & 21 & 19 & 16 & 16 \\
\hline Piauí & $-1,03 \%$ & $-0,78 \%$ & $-0,56 \%$ & $-0,43 \%$ & 15 & 15 & 15 & 15 \\
\hline Ceará & $-1,73 \%$ & $-1,28 \%$ & $-0,94 \%$ & $-0,73 \%$ & 4 & 4 & 4 & 5 \\
\hline Rio Grande do Norte & $0,19 \%$ & $0,01 \%$ & $0,00 \%$ & $0,01 \%$ & 24 & 24 & 24 & 24 \\
\hline Paraíba & $-0,89 \%$ & $-0,71 \%$ & $-0,51 \%$ & $-0,38 \%$ & 18 & 16 & 17 & 18 \\
\hline Pernambuco & $-1,30 \%$ & $-1,12 \%$ & $-0,84 \%$ & $-0,65 \%$ & 10 & 8 & 8 & 8 \\
\hline Alagoas & $2,38 \%$ & $0,62 \%$ & $0,20 \%$ & $0,07 \%$ & 27 & 26 & 25 & 25 \\
\hline Sergipe & $-1,29 \%$ & $-1,08 \%$ & $-0,80 \%$ & $-0,62 \%$ & 11 & 9 & 10 & 10 \\
\hline Bahia & $-0,76 \%$ & $-0,59 \%$ & $-0,43 \%$ & $-0,33 \%$ & 19 & 20 & 20 & 21 \\
\hline \multicolumn{9}{|c|}{ Sudeste } \\
\hline Minas Gerais & $-1,13 \%$ & $-0,91 \%$ & $-0,67 \%$ & $-0,51 \%$ & 13 & 13 & 13 & 13 \\
\hline Espírito Santo & $-1,05 \%$ & $-0,82 \%$ & $-0,61 \%$ & $-0,47 \%$ & 14 & 14 & 14 & 14 \\
\hline Rio de Janeiro & $-1,50 \%$ & $-1,22 \%$ & $-0,92 \%$ & $-0,72 \%$ & 6 & 7 & 7 & 7 \\
\hline São Paulo & $-2,13 \%$ & $-1,61 \%$ & $-1,19 \%$ & $-0,92 \%$ & 1 & 1 & 1 & 1 \\
\hline \multicolumn{9}{|c|}{ Sul } \\
\hline Paraná & $-1,74 \%$ & $-1,35 \%$ & $-1,01 \%$ & $-0,79 \%$ & 3 & 3 & 3 & 3 \\
\hline Santa Catarina & $-1,64 \%$ & $-1,25 \%$ & $-0,94 \%$ & $-0,73 \%$ & 5 & 5 & 6 & 6 \\
\hline Rio Grande do Sul & $-1,85 \%$ & $-1,43 \%$ & $-1,07 \%$ & $-0,83 \%$ & 2 & 2 & 2 & 2 \\
\hline \multicolumn{9}{|c|}{ Centro-Oeste } \\
\hline Mato Grosso do Sul & $-1,36 \%$ & $-1,07 \%$ & $-0,81 \%$ & $-0,63 \%$ & 9 & 10 & 9 & 9 \\
\hline Mato Grosso & $-1,40 \%$ & $-1,03 \%$ & $-0,76 \%$ & $-0,59 \%$ & 7 & 11 & 11 & 11 \\
\hline Goiás & $-1,19 \%$ & $-0,95 \%$ & $-0,72 \%$ & $-0,56 \%$ & 12 & 12 & 12 & 12 \\
\hline Distrito Federal & $-0,92 \%$ & $-0,68 \%$ & $-0,50 \%$ & $-0,39 \%$ & 17 & 18 & 18 & 17 \\
\hline
\end{tabular}


A ordem relativa das Unidades Federativas permanece praticamente igual com o passar do tempo, indicando uma dinâmica relativamente parecida entre elas. Pequenas mudanças de posição ocorrem, mas são raros os casos em que um Estado ganhe ou perca muitas posições. O Estado do Amazonas parece ser uma das poucas exceções. Se após um ano ele se apresentava como o oitavo Estado mais sensível, após quatro anos ele subiu para a quarta posição, indicando uma dinâmica um pouco mais lenta do que a dos demais. 


\section{POR QUE OS ESTADOS RESPONDEM DE FORMA DIFERENTE A UM CHOQUE DE POLÍTICA MO- NETÁRIA?}

\subsection{Metodologia}

\subsubsection{Bayesian Model Averaging}

Em diversas aplicações empíricas existe um grande número de covariadas que, em teoria, podem influenciar a variável dependente. Nesses casos, muitas vezes não é claro qual procedimento o pesquisador deve seguir. Incluir todas as variáveis no modelo pode ser uma opção. Contudo, esse procedimento é insatisfatório, uma vez que a inclusão de variáveis irrelevantes pode reduzir a precisão de todos os estimadores. Dessa forma, o procedimento tradicional seria conduzir uma série de testes no intuito de selecionar um modelo final no qual as variáveis irrelevantes estariam omitidas.

Apesar de vários trabalhos empíricos procederem dessa forma, existem alguns problemas associados a essa metodologia ${ }^{20}$. Em primeiro lugar, ao realizar tais testes para se escolher um modelo, existe a possibilidade de o pesquisador rejeitar o melhor modelo e acabar escolhendo um modelo pior. A probabilidade desse tipo de erro acontecer aumenta rapidamente conforme o pesquisador realiza os testes. Em segundo lugar, mesmo que tais sequências de testes apontem para um melhor modelo, é raramente desejável apresentar as evidências provenientes desse modelo e simplesmente rejeitar os resultados obtidos a partir dos outros modelos, uma vez que o pesquisador estaria ignorando a incerteza existente sobre qual modelo utilizar.

A estatística Bayesiana apresenta uma metodologia simples e consistente para lidar com esse tipo de incerteza, o Bayesian Model Averaging (BMA). Defina um modelo como um conjunto de variáveis explicativas em uma regressão linear. Dessa forma, a inclusão ou exclusão de uma variável explicativa constitui um novo modelo. Suponha que existam $K$ candidatos a possíveis variáveis explicativas. Isso significa que temos $2^{K}$ possíveis modelos.

\footnotetext{
${ }^{20}$ Para uma discussão mais detalhada do tema, ver Poirier (1995), Draper (1995) e Hodges (1987).
} 
Formalizando um pouco mais, defina cada um dos $R$ modelos diferentes por $M_{r}$, onde $r=1, \ldots, R$. Seja $y=\left(y_{1}, \ldots, y_{N}\right)^{\prime}$ um vetor $N \times 1$, onde $N$ é o número de observações disponíveis. Seja $X$ uma matriz $N \times K$ que dispõe em cada linha as $K$ covariadas para cada um $\operatorname{dos} N$ indivíduos. Defina ainda $X_{r}$ como uma matriz $N \times k_{r}$ que dispõe em cada linha $k_{r}$ covariadas para cada um dos $N$ indivíduos, onde $k_{r}$ é um subconjunto de $K$. Por fim, seja $\beta_{r}$ o vetor $k_{r} \times 1$ de coeficientes, $\varepsilon$ como um vetor $N \times 1$ de erros onde $\varepsilon \sim N\left(0_{N}, h^{-1} I_{N}\right)$ e $\imath_{N}$ um vetor $N \times 1$ de uns.

Dessa forma, cada um dos $R$ modelos de regressão linear pode ser definido como

$$
y=\alpha l_{N}+X_{r} \beta_{r}+\varepsilon
$$

Observe que a constante $\alpha$ e a variância $h^{-1}$ não apresentam subscrito $r$ referente ao modelo. Isso ocorre devido à suposição de que esses parâmetros são comuns a todos os modelos. Dessa forma, o que muda entre os modelos é a matriz de covariadas $X_{r}$, que contém algumas, ou até todas, colunas de $X$. Uma vez que existem $2^{K}$ subconjuntos de $X$, temos $R=2^{K}$ possíveis modelos.

Com as hipóteses acima, a função de verossimilhança pode ser escrita como

$$
p\left(y \mid \alpha, \beta_{r}, h\right)=\frac{h_{\overline{2}}^{N}}{(2 \pi) \frac{N}{2}}\left\{\exp \left[-\frac{h}{2}\left(y-\alpha \imath_{N}-X_{r} \beta_{r}\right)^{\prime}\left(y-\alpha \imath_{N}-X_{r} \beta_{r}\right)\right]\right\}
$$

Quanto à prior, é conveniente dividir os parâmetros entre os que não variam $(\alpha, h)$ e os que variam entre os modelos $\left(\beta_{r}\right)$. Segundo Koop (2003), ao comparar modelos usando a posterior odds ratio, é aceitável usar priors não informativas para os parâmetros comuns a todos os modelos. Dessa forma, consideraremos:

$$
p(h) \propto \frac{1}{h}
$$

$$
p(\alpha) \propto 1
$$


Fernandez et al (2001a) sugerem subtrair todas as covariadas de suas respectivas médias. Quando as variáveis explicativas são medidas como desvio de suas médias, elas possuem média zero. Como os erros $\varepsilon$ também apresentam média zero, apesar dos coeficientes de inclinação não mudarem, o intercepto se torna a média da variável dependente. Dessa forma, garante-se que a prior não informativa de $\alpha$ tenha a mesma implicação para todos os modelos.

Já para $\beta_{r}$, será considerada a prior conjugada Normal-Gamma:

$$
\beta_{r} \mid h \sim N\left(\underline{\beta}_{r}, h^{-1} \underline{V}_{r}\right)
$$

Baseando-se na crença de que várias covariadas utilizadas são irrelevantes, a prior de $\beta_{r}$ será centrada em $\beta_{r}=0_{k_{r}}$. Já para a variância, será utilizada a $g$-prior ${ }^{21}$, descrita em Zellner (1986). Intuitivamente, a g-prior sugere que a matriz de variância covariância da prior de $\beta_{r}$ é proporcional à matriz de variância covariância fornecida pelos dados. Formalmente

$$
\underline{V}_{r}=\left[g_{r} X_{r}^{\prime} X_{r}\right]^{-1}
$$

A g-prior facilita a escolha da prior uma vez que reduz a escolha de parâmetros para apenas um hiper parâmetro $g_{r}$. Fernandez et al (2001a) sugerem que

$$
g_{r}=\left\{\begin{array}{cl}
\frac{1}{K^{2}} & N \leq K^{2} \\
\frac{1}{N} & N>K^{2}
\end{array}\right.
$$

A escolha da prior acima, junto com a função de verossimilhança Normal, implica em uma distribuição $t$ multivariada para o vetor de parâmetros $\left(\alpha, \beta_{r}\right)$ e uma distribuição Gamma para $h$. Integrando $h$ e $\alpha$ da posterior de $\left(\alpha, \beta_{r}, h\right)$ obtém-se que a posterior marginal de $\beta_{r}$ é uma uma distribuição $t$ multivariada de média

\footnotetext{
${ }^{21}$ Além de reduzir a escolha dos hiper parâmetros para apenas um escalar, a $g$-prior também apresenta outras propriedades interessantes, como permitir o calculo analítico da likelihood marginal e apresentar resultados satisfatórios do ponto de vista preditivo. Para uma discussão mais detalhada das propriedades da g-prior ver Fernandez et al (2001a).
} 


$$
E\left(\beta_{r} \mid y, M_{r}\right) \equiv \overline{\beta_{r}}=\bar{V}_{r} X_{r}^{\prime} y
$$

e matriz de covariância

$$
\operatorname{var}\left(\beta_{r} \mid y, M_{r}\right)=\frac{\bar{v} \bar{s}_{r}^{2}}{\bar{v}-2} \bar{V}_{r}
$$

e $\bar{v}=N$ graus de liberdade. Adicionalmente

$$
\bar{V}_{r}=\left[\left(1+g_{r}\right) X_{r}^{\prime} X_{r}\right]^{-1}
$$

$\mathrm{e}$

$$
\bar{s}_{r}^{2}=\frac{\frac{1}{g_{r}+1} y^{\prime} P_{X_{r}} y+\frac{g_{r}}{g_{r}+1}\left(y-\bar{y} \iota_{N}\right)^{\prime}\left(y-\bar{y} \iota_{N}\right)}{\bar{v}}
$$

onde

$$
P_{X_{r}}=I_{N}-X_{r}\left(X_{r}^{\prime} X_{r}\right)^{-1} X_{r}^{\prime}
$$

Considerando priors iguais para cada modelo, na forma

$$
p\left(M_{r}\right)=\frac{1}{R}
$$

temos que a posterior do modelo $M_{r}$ pode ser escrita como

$$
p\left(M_{r} \mid y\right)=\frac{p\left(y \mid M_{r}\right)}{\sum_{j=1}^{R} p\left(y \mid M_{j}\right)}
$$

aonde a likelihood marginal é proporcional a

$$
p\left(y \mid M_{r}\right) \propto\left(\frac{g_{r}}{g_{r+1}}\right)^{\frac{k_{r}}{2}}\left[\frac{1}{g_{r}+1} y^{\prime} P_{X_{r}} y+\frac{g_{r}}{g_{r}+1}\left(y-\bar{y} \iota_{N}\right)^{\prime}\left(y-\bar{y} \iota_{N}\right)\right]^{-\frac{N-1}{2}}
$$

Defina $\phi$ como o parâmetro de interesse. É possível demonstrar que tudo o que é conhecido sobre $\phi$ pode ser resumido em sua posterior e que 


$$
p(\phi \mid y)=\sum_{r=1}^{R} p\left(\phi \mid y, M_{r}\right) p\left(M_{r} \mid y\right)
$$

Sendo $g(\phi)$ uma função de $\phi$ as regras da esperança condicional implicam que

$$
E[g(\phi) \mid y]=\sum_{r=1}^{R} E\left[g(\phi) \mid y, M_{r}\right] p\left(M_{r} \mid y\right)
$$

Dessa forma, ao levar em consideração a incerteza existente em relação ao modelo utilizado, a média da função $g(\phi)$ do parâmetro de interesse torna-se a média das médias de cada um dos $R$ modelos diferentes, ponderada pela posterior $p\left(M_{r} \mid y\right)$ de cada modelo.

\subsubsection{Markov Chain Monte Carlo Model Composition}

Uma vez definido o modelo $M_{r}$ e o hiper parâmetro $g_{r}$, é possível construir todas as equações acima e avaliar as probabilidades de interesse. Contudo, conforme o número de covariadas aumenta, o número de possíveis modelos cresce de maneira explosiva, impossibilitando a construção de cada equação para todo $M_{r}$, onde $r=1, \ldots, R$. Dessa forma, faz-se necessário utilizar algum algoritmo que permita aplicar o BMA sem avaliar todos os possíveis modelos. Um algoritmo bastante utilizado na literatura é o Markov Chain Monte Carlo Model Composition $\left(M C^{3}\right)$, desenvolvido por Madigan et al (1995).

Os algoritmos de Markov Chain Monte Carlo (MCMC) simulam sorteios de uma posterior sorteando mais parâmetros de regiões de maior probabilidade e menos parâmetros de regiões com menor probabilidade. Dessa forma, tais algoritmos evitam sortear em todo o espaço de parâmetros. A diferença entre os algoritmos de $M C M C$ e o $M C^{3}$ é que o último é construído para sortear modelos ao invés de parâmetros. Uma vez que percorrer todo o espaço de modelos seria muito custoso computacionalmente, o $M C^{3}$ foca nos modelos com maior probabilidade.

O algoritmo $M C^{3}$ é baseado no algoritmo de Metropolis-Hastings. Seja $M^{(s)}$ uma sequência de modelos, onde $s=1, \ldots, S$. Cada $M^{(s)}$ é uma realização de um dos $M_{r}$ possíveis modelos. $\mathrm{O} M C^{3}$ é implementado da seguinte maneira: 
1. Comece com um modelo $M^{0}$. Uma possível alternativa é estimar uma regressão linear por mínimos quadrados ordinários com todas as covariadas e excluir aquelas cuja estatística $t$ for menor do que 0,5 .

2. Escolha aleatoriamente (com probabilidades iguais) um candidato $M^{*}$. Esse candidato será sorteado do subconjunto de $\left\{M_{1}, \ldots, M_{R}\right\}$ que inclui o modelo atual $M^{s-1}$, todos os modelos que incluem uma nova covariada à $M^{s-1}$ e todos os modelos que excluem uma covariada de $M^{s-1}$.

3. Aceite o candidato $M^{*}$ com probabilidade ${ }^{22}$

$$
\alpha\left(M^{(s-1)}, M^{*}\right)=\min \left[\frac{p\left(y \mid M^{*}\right) p\left(M^{*}\right)}{p\left(y \mid M^{(s-1)}\right) p\left(M^{(s-1)}\right)}, 1\right]
$$

4. Caso $M^{*}$ seja aceito, $M^{*}=M^{s}$. Caso contrário, $M^{*}=M^{s-1}$, ou seja, volta-se ao modelo anterior.

5. Para evitar a influência do modelo inicial $M^{0}$, as primeiras $S_{0}$ repetições do algoritmo são descartadas e as quantidades de interesse são calculadas com base nas próximas $S_{1}$ repetições, onde $S=S_{0}+S_{1}$.

Uma vez calculada a sequência $\left\{M^{1}, \ldots, M^{S}\right\}$ é possível aproximar (40) a partir de

$$
\hat{g}=\frac{1}{S_{1}} \sum_{s=S_{0}+1}^{S} E\left[g(\phi) \mid y, M^{(s)}\right]
$$

dado que $\hat{g} \rightarrow E[g(\phi) \mid y]$ conforme $S_{1} \rightarrow \infty$.

\subsection{Base de dados: Segunda etapa}

O conjunto de variáveis utilizado para identificar quais canais de transmissão são importantes na determinação das assimetrias entre os estados brasileiros pode ser dividido em quatro grandes grupos: mix de produção, sistema financeiro, característica das empresas

$$
{ }^{22} \text { Como por hipótese } p\left(M^{*}\right)=p\left(M^{(s-1)}\right)=\frac{1}{R}, \alpha\left(M^{(s-1)}, M^{*}\right)=\min \left[\frac{p\left(y \mid M^{*}\right)}{p\left(y \mid M^{(s-1)}\right)}, 1\right] .
$$


e demográfico e socioeconômico. Uma descrição detalhada das variáveis encontra-se na tabela 8 .

Como o perfil dessas variáveis mudou muito ao longo da última década, optou-se por construir médias a partir das séries temporais originais, de forma a cobrir um intervalo de tempo o mais parecido possível com o utilizado no SVAR. Contudo, sua abrangência temporal varia caso a caso, devido às diferentes frequências e disponibilidade de cada fonte de dados.

O mix de produção é composto pela porcentagem de ocupados - com mais de 18 anos - nos seguintes setores: serviços, agropecuária, comércio, construção, indústria extrativa mineral, indústria de transformação, serviços industriais de utilidade pública (SIUP) e setor público. As séries são disponibilizadas pelo IPEA $^{23}$, e foram construídas com base nos censos populacionais de 2000 e 2010, ambos do IBGE.

Como sugerem Carlino e Defina (1999), o mix de produção de um Estado pode ser usado como uma proxy para o canal de juros. Setores como o da indústria de transformação seriam mais sensíveis à taxa de juros, uma vez que são mais dependentes de crédito. A mesma lógica pode ser aplicada ao setor de construção (FRANCIS et al, 2012). Já setores como a indústria extrativa mineral e o agropecuário estariam correlacionados com o canal de câmbio, dada sua maior interdependência com o comércio exterior.

Para o sistema financeiro, as variáveis utilizadas são a razão entre o saldo das operações de crédito - pessoa física e jurídica - e o PIB estadual, número de agências bancárias por 100 mil habitantes e a proporção de municípios sem agência bancária ou posto de atendimento bancário $(\mathrm{PAB})$.

A razão crédito/PIB foi construída utilizando os dados de saldo de operações de crédito $^{24}$ disponibilizados pelo Banco Central do Brasil (BCB) e os dados de PIB estadual calculados pelo IBGE. Como a série de saldo de crédito é mensal, foi construída uma média para cada ano, que então foi dividida pelo valor do PIB estadual, dado que este último apresenta periodicidade anual. Uma média final foi calculada para o período de 2004 a 2010.

\footnotetext{
${ }^{23}$ As séries podem ser encontradas na seção social do Ipeadata.

${ }^{24}$ Essa série consiste no valor presente de todos os empréstimos superiores a $\mathrm{R} \$ 1$ mil reais, registrados no Sistema de Informações de Crédito (SCR) com base no endereço fiscal de cada devedor.
} 
Já as últimas duas variáveis do grupo do sistema financeiro foram construídas com base nos dados do sistema de cadastro unificado do $\mathrm{BC}$, o Unicad. O número de agências bancárias por 100 mil habitantes ${ }^{25}$ consiste na média dessa razão, para o período de dezembro de 1998 a junho de 2013. A proporção de municípios sem agência ou PAB é formada pela média dessa variável, entre dezembro de 1998 e maio de 2012 - com a exclusão do período entre setembro de 2005 a setembro de 2007.

O grupo de variáveis sobre as características das empresas e bancos é composto pela proporção de firmas com até 49 funcionários, a proporção das firmas de serviços financeiros com até 49 funcionários e a proporção de empregados em firmas de até 49 funcionários. As três variáveis foram construídas a partir do Cadastro Central de Empresas (CEMPRE), do IBGE, e são médias para o período de 2006 a 2011. Essas variáveis servem de proxy para o canal de crédito, já que o problema de assimetria de informação estaria mais presente em firmas e bancos menos desenvolvidos (CARLINO; DEFINA, 1999).

Por fim, o grupo de variáveis demográficas e socioeconômicas é composto pela média dos anos de estudos para pessoas com 25 , ou mais, anos de idade, densidade demográfica ${ }^{26}$, número de homicídios por 100 mil habitantes, proporção dos indivíduos com renda domiciliar per capita igual ou inferior a $\mathrm{R} \$ 140,00$ mensais (em reais de agosto de 2010) e renda domiciliar per capita média (em reais de outubro de 2012). Essas variáveis foram incluídas na tentativa de se capturar características estaduais mais gerais que possam impactar na resposta regional a um choque de política monetária (CARLINO; DEFINA, 1999; ROCHA et al, 2011).

\footnotetext{
${ }^{25}$ A estimativa mensal da população de cada unidade federativa foi calculada pela interpolação linear dos censos demográficos de 1991, 2000 e 2010 e das contagens populacionais de 1996 e 2007, todos calculados pelo IBGE.

${ }^{26}$ Número de habitantes por quilômetro quadrado.
} 
Tabela 8: Fonte de Dados

\begin{tabular}{|c|c|c|c|}
\hline Variável & Freq. $^{a}$ & Período & Fonte \\
\hline \multicolumn{4}{|c|}{ Demográfico e Socioeconômico } \\
\hline Anos de Estudo & A & 1996 a 2012 & IPEA $^{b}$ \\
\hline Habitantes $/ \mathrm{Km}^{2}$ & $\mathrm{D}$ & 2000,2010 & Censo - IBGE \\
\hline Homicídios/100 mil Hab. & A & 1996 a 2009 & SIM-DATASUS $^{\mathrm{b}}$ \\
\hline Indivíduos Abaixo da Linha de Pobreza (\%) & $\mathrm{D}$ & $1991,2000,2010$ & Censo - IBGE ${ }^{\mathrm{b}}$ \\
\hline Renda Domiciliar Per Capita & A & 1996 a 2012 & Pnad - IBGE ${ }^{b}$ \\
\hline \multicolumn{4}{|c|}{ Sistema Financeiro } \\
\hline Saldo de Operações de Crédito/PIB - PF & $\mathrm{M}$ & jan/2004 a jun/2013 & SCR - BCB \\
\hline Saldo de Operações de Crédito/PIB - PJ & M & jan/2004 a jun/2013 & SCR - BCB \\
\hline Agências/ 100 mil Hab. & M & $\mathrm{dez} / 1998$ a jun/2013 & Unicad - BCB \\
\hline Municípios Sem Agência e PAB (\%) & M & dez/1998 a mai/2012 & Unicad - BCB \\
\hline \multicolumn{4}{|c|}{ Mix Produtivo $^{\mathrm{b}}$} \\
\hline Serviços - Ocupados (\%) & $\mathrm{D}$ & 2000,2010 & Censo - IBGE \\
\hline Comércio - Ocupados (\%) & $\mathrm{D}$ & 2000,2010 & Censo - IBGE \\
\hline Agropecuária - Ocupados (\%) & $\mathrm{D}$ & 2000,2010 & Censo - IBGE \\
\hline Extrativo Mineral - Ocupados (\%) & $\mathrm{D}$ & 2000,2010 & Censo - IBGE \\
\hline Transformação - Ocupados (\%) & $\mathrm{D}$ & 2000,2010 & Censo - IBGE \\
\hline Construção - Ocupados (\%) & $\mathrm{D}$ & 2000,2010 & Censo - IBGE \\
\hline SIUP - Ocupados $(\%)$ & $\mathrm{D}$ & 2000,2010 & Censo - IBGE \\
\hline Setor Público - Ocupados (\%) & $\mathrm{D}$ & 2000,2010 & Censo - IBGE \\
\hline \multicolumn{4}{|c|}{ Características das Empresas } \\
\hline Empresas - Até 49 Funcionários - Serviços Financeiros (\%) & A & 2006 a 2011 & CEMPRE - IBGE \\
\hline Empresas - Até 49 Funcionários (\%) & A & 2006 a 2011 & CEMPRE - IBGE \\
\hline Empresas - Até 49 Funcionários - Empregados (\%) & A & 2006 a 2011 & CEMPRE - IBGE \\
\hline
\end{tabular}

\subsection{Resultados: BMA $^{27}$}

Utilizando as medidas de sensibilidade derivadas do VAR Bayesiano, o Bayesian Model Averaging foi executado com seis variáveis dependentes diferentes, sendo elas: a resposta relativa acumulada em 48 períodos, a resposta relativa acumulada em 48 períodos levando em conta os Intervalos de Credibilidade de $68 \%$ e $90 \%$, a resposta relativa acumulada máxima e a resposta relativa acumulada máxima levando em conta os Intervalos de Credibilidade de $68 \%$ e $90 \%$. Para facilitar a análise dos resultados, as medidas de sensibilidade foram multiplicadas por -100 , de forma que um coeficiente positivo deve ser interpretado como o aumento, em pontos percentuais, da sensibilidade em relação a uma inovação monetária.

Como sugere Fernandez et al (2001b), uma forma de verificar a convergência do algo-

\footnotetext{
${ }^{27}$ Para implementar o BMA, foi utilizado software estatístico $R$, juntamente com o pacote BMS, disponível em http://bms.zeugner.eu/getBMS/. Para aqueles familiarizados com o software Matlab, é possível reproduzir o exemplo apresentado em Koop (2003), p. 274-278 (além de qualquer outra aplicação desejada), com o código disponível em http://www.wiley.com/legacy/wileychi/koopbayesian/mainprograms.html, capítulo 11. Por fim, ainda é possível consultar o código de Matlab utilizado por Francis et al (2012) em http://www.tateviksekhposyan.org/.
} 
Tabela 9: Estatísticas Descritivas

\begin{tabular}{|c|c|c|c|c|}
\hline Variável & Média & Desv. Padrão & Máx. & Min. \\
\hline \multicolumn{5}{|c|}{ Demográfico e Socioeconômico } \\
\hline Anos de Estudo & 6,06 & 1,03 & 8,85 & 4,39 \\
\hline Habitantes $/ \mathrm{Km}^{2}$ & 61,69 & 92,65 & 384,57 & 1,58 \\
\hline Homicídios/100 mil Hab. & 26,18 & 11,88 & 52,12 & 9,79 \\
\hline Indivíduos Abaixo da Linha de Pobreza (\%) & 33,61 & 14,60 & 58,53 & 8,48 \\
\hline Renda Domiciliar Per Capita & 654,72 & 245,65 & 1459,24 & 357,10 \\
\hline \multicolumn{5}{|c|}{ Sistema Financeiro } \\
\hline Saldo de Operações de Crédito/PIB - PF & 13,82 & 4,06 & 25,50 & 6,84 \\
\hline Saldo de Operações de Crédito/PIB - PJ & 12,81 & 4,35 & 21,09 & 4,98 \\
\hline Agências/ 100 mil Hab. & 7,96 & 3,66 & 15,13 & 3,95 \\
\hline Municípios Sem Agência e PAB (\%) & 38,55 & 22,62 & 81,20 & 0,57 \\
\hline \multicolumn{5}{|l|}{ Mix Produtivo } \\
\hline Serviços - Ocupados (\%) & 44,00 & 6,67 & 65,88 & 34,40 \\
\hline Comércio - Ocupados (\%) & 14,61 & 0,97 & 16,45 & 13,06 \\
\hline Agropecuária - Ocupados (\%) & 19,68 & 8,23 & 36,72 & 1,77 \\
\hline Extrativo Mineral - Ocupados (\%) & 0,45 & 0,31 & 1,21 & 0,05 \\
\hline Transformação - Ocupados (\%) & 9,78 & 4,08 & 21,69 & 4,46 \\
\hline Construção - Ocupados (\%) & 7,18 & 0,72 & 8,74 & 5,70 \\
\hline SIUP - Ocupados $(\%)$ & 0,75 & 0,12 & 1,08 & 0,53 \\
\hline Setor Público - Ocupados (\%) & 7,53 & 3,25 & 18,38 & 3,79 \\
\hline \multicolumn{5}{|c|}{ Características das Empresas } \\
\hline Empresas - Até 49 Funcionários - Serviços financeiros (\%) & 97,42 & 1,93 & 100,00 & 90,28 \\
\hline Empresas - Até 49 Funcionários (\%) & 98,09 & 0,49 & 98,74 & 96,25 \\
\hline Empresas - Até 49 Funcionários - Empregados (\%) & 36,59 & 7,87 & 49,31 & 21,20 \\
\hline
\end{tabular}


Tabela 10: Convergência $M C^{3}$

\begin{tabular}{lcccccc}
\hline & Total & $\begin{array}{c}\text { Total I.C. } \\
68 \%\end{array}$ & $\begin{array}{c}\text { Total I.C. } \\
90 \%\end{array}$ & Máx. & $\begin{array}{c}\text { Máx. I.C. } \\
68 \%\end{array}$ & $\begin{array}{c}\text { Máx. I.C. } \\
90 \%\end{array}$ \\
\hline \hline Corr. PMP & 0,9994 & 0,9987 & 0,9996 & 0,9993 & 0,9992 & 0,9996 \\
\hline
\end{tabular}

ritmo $M C^{3}$ é obter a correlação entre a posterior analítica do modelo $M_{r}$, calculada a partir da equação (37), e a posterior empírica do modelo $M_{r}$, obtida a partir da proporção entre a quantidade de vezes que um modelo é sorteado e o número total de sorteios realizados. Os resultados para os 6 modelos estão na tabela 10 e indicam uma boa convergência do algoritmo $M C^{3}$.

Nas tabelas 11 e 12 encontram-se os resultados para os modelos estimados, tanto os obtidos a partir da resposta relativa acumulada em 48 períodos, quanto os obtidos a partir da resposta relativa acumulada máxima. A coluna intitulada Posterior Inclusion Probability $(P I P)$ contém a probabilidade de determinada variável estar inclusa no modelo ${ }^{28}$. O PIP é estimado pela proporção de modelos sorteados que incluem determinada covariada. Já as colunas Post Mean e Post SD representam, respectivamente, a média e o desvio padrão da posterior, e são estimadas conforme a equação (42).

A análise da PIP mostra que existe um grau elevado de incerteza em relação à importância das covariadas para a determinação da sensibilidade de determinada unidade federativa a um choque de política monetária. Em nenhuma das seis especificações utilizadas uma variável apresentou PIP superior à $90 \%$.

O fato da variável dependente derivar de uma distribuição de funções impulso resposta, que por si só já apresenta um certo grau de incerteza, pode influenciar o resultado. Contudo, mesmo considerando apenas respostas com grau reduzido de incerteza em relação ao seu sinal, a presença de PIP baixas ainda é predominante.

A variável que mais se destaca por apresentar PIP relativamente elevado é a porcentagem da população ocupada empregada na indústria de transformação. No modelo construído a partir da resposta relativa acumulada, essa variável é incluída em 57\% dos modelos sorteados, valor bastante elevado se comparado com as demais covariadas. Ao passar do

\footnotetext{
${ }^{28} \mathrm{~A}$ constante apresenta $P M P$ igual a 1 por construção.
} 
modelo construído a partir da mediana de função de impulso resposta, para os modelos que consideram os Intervalos de Credibilidade de 68\% e 90\%, a PIP da indústria de transformação aumenta para $60 \%$ e $88 \%$, respectivamente. Dessa forma, ao limpar a medida de sensibilidade daquelas Unidades Federativas cujo sinal da resposta apresenta grau elevado de incerteza, considerando-as como insensíveis à política monetária, a importância da presença da indústria de transformação cresce consideravelmente.

O mesmo resultado é encontrado analisando os modelos que consideram a resposta relativa acumulada máxima. Ao construir a variável dependente com base na mediana da função impulso resposta, o PIP da indústria de transformação é de $25 \%$. Ao passar para os modelos que consideram os Intervalos de Credibilidade de $68 \%$ e $90 \%$, a probabilidade de inclusão aumenta para $57 \%$ e $88 \%$, respectivamente.

Apesar de, em menor grau, outras covariadas relacionadas ao mix produtivo se destacam quando a análise foca em seus respectivos PIP. Para a resposta total restrita pelo Intervalo de Credibilidade de 90\%, os percentuais de ocupados empregados no setor extrativo mineral, agropecuária e serviços, são inclusos em 39\%, 25\%, 24\% dos modelos sorteados, respectivamente. Percentuais de inclusão parecidos são encontrados quando a análise se volta para a resposta relativa acumulada máxima restrita ao mesmo Intervalo de Credibilidade.

Diferentemente do encontrado para as variáveis relacionadas ao mix produtivo, as variáveis que tentam capturar a presença do canal de crédito através de características das firmas e bancos aparentam ser, de forma geral, pouco relevantes para se explicar a sensibilidade das Unidades Federativas brasileiras a um choque de política monetária. Com poucas exceções, a probabilidade de inclusão dessas variáveis é baixa, com valores inferiores à $10 \%$.

Da mesma forma, variáveis relacionadas às características socioeconômicas e penetração do sistema financeiro também apresentam probabilidade de inclusão relativamente pequena. Uma exceção interessante é a quantidade de agências bancárias para cada 100 mil habitantes. Na especificação que se utiliza da resposta total, essa variável apresenta probabilidade de inclusão superior à 30\%. Quando restringimos a resposta total a partir do Intervalo de Credibilidade de 68\%, essa probabilidade sobe para 59\%. 
A segunda coluna das tabelas 11 e 12 apresenta a média da distribuição posterior. Ela é calculada utilizando as equações (32) e (42), representando uma média ponderada das médias de cada modelo sorteado. A média das varáveis excluídas de um determinado modelo é zero, de forma que desconsiderar a incerteza acerca do modelo correto superestima o valor dos coeficientes.

Como é possível observar, a maioria das variáveis com PIP alto apresenta sinais coerentes com a teoria econômica. O coeficiente da porcentagem de ocupados empregados na indústria de transformação apresenta média positiva para todas as especificações. Para a resposta total, um aumento de $1 \%$ no share desse setor no emprego eleva a sensibilidade a um choque de política monetária em 0.0291p.p., valor que aumenta para 0.351p.p. quando consideramos o Intervalo de Credibilidade de $90 \%$.

Ainda se restringindo às variáveis relativas ao mix produtivo, é possível concluir que quanto maior o share do setor agropecuário e extrativo mineral no emprego, menos sensível a unidade federativa se torna a uma inovação monetária. Um aumento da parcela de pessoas ocupadas empregadas pelo setor de serviços também atua no mesmo sentido. Já um aumento da porcentagem de ocupados trabalhando no comércio e construção tende a aumentar a sensibilidade à política monetária. Por fim, a maioria das especificações aponta que um aumento da porcentagem de ocupados empregados no setor público diminui a sensibilidade à política monetária.

Apesar da baixa probabilidade de inclusão, a média dos coeficientes das covariadas relativas ao canal de crédito é consistentes com a teoria econômica. Em sua grande maioria, apontam que quanto maior a proporção de firmas pequenas e de trabalhadores empregados em firmas pequenas, tanto no setor financeiro, como nos outros setores, maior a sensibilidade a um choque de política monetária.

As variáveis relativas à inserção do mercado financeiro nos Estados também estão em linha com a intuição econômica. Quanto maior o número de agências por 100 mil habitantes e quanto menor o número de municípios sem agência ou posto de atendimento bancário, maior é a porcentagem de empregos perdidos devido a um choque monetário. 
Tabela 11: Importância dos Canais de Transmissão - Resposta Total

\begin{tabular}{|c|c|c|c|c|c|c|c|c|c|}
\hline \multirow{2}{*}{ Covariadas } & \multicolumn{3}{|c|}{ Resposta Total } & \multicolumn{3}{|c|}{ I.C. $68 \%$} & \multicolumn{3}{|l|}{ I.C. $90 \%$} \\
\hline & PIP & Post Mean & Post SD & PIP & Post Mean & Post SD & PIP & Post Mean & Post SD \\
\hline Constante & 1,0000 & $-0,7803$ & - & 1,0000 & $-1,4487$ & - & 1,0000 & $-1,2567$ & \\
\hline Anos de Estudo & 0,0702 & 0,0024 & 0,0372 & 0,1035 & $-0,0068$ & 0,0322 & 0,0911 & $-0,0026$ & 0,0236 \\
\hline Habitantes $/ \mathrm{Km}^{2}$ & 0,1991 & 0,0003 & 0,0007 & 0,1746 & 0,0001 & 0,0004 & 0,1482 & 0,0001 & 0,0002 \\
\hline Homicídios/100 mil Hab. & 0,0725 & 0,0001 & 0,0018 & 0,0911 & 0,0003 & 0,0015 & 0,0584 & 0,0000 & 0,0008 \\
\hline Indivíduos Abaixo da Linha de Pobreza (\%) & 0,1021 & 0,0005 & 0,0051 & 0,1954 & 0,0019 & 0,0055 & 0,0898 & 0,0002 & 0,0023 \\
\hline Renda Domiciliar Per Capita & 0,0884 & 0,0000 & 0,0002 & 0,2043 & $-0,0001$ & 0,0003 & 0,0958 & 0,0000 & 0,0001 \\
\hline Saldo de Operações de Crédito/PIB - PF & 0,0657 & $-0,0003$ & 0,0042 & 0,1102 & 0,0011 & 0,0048 & 0,0573 & 0,0002 & 0,0020 \\
\hline Saldo de Operações de Crédito/PIB - PJ & 0,0706 & 0,0011 & 0,0070 & 0,2183 & 0,0046 & 0,0106 & 0,0780 & 0,0007 & 0,0039 \\
\hline Agências/ 100 mil Hab. & 0,3219 & 0,0215 & 0,0375 & 0,5911 & 0,0394 & 0,0409 & 0,1855 & 0,0051 & 0,0141 \\
\hline Municípios Sem Agência e PAB (\%) & 0,1688 & $-0,0009$ & 0,0026 & 0,2090 & $-0,0008$ & 0,0019 & 0,1073 & $-0,0002$ & 0,0008 \\
\hline Serviços - Ocupados (\%) & 0,3087 & $-0,0117$ & 0,0228 & 0,1128 & $-0,0010$ & 0,0072 & 0,2413 & $-0,0014$ & 0,0119 \\
\hline Comércio - Ocupados (\%) & 0,4316 & 0,0667 & 0,0893 & 0,4161 & 0,0406 & 0,0552 & 0,0916 & 0,0031 & 0,0151 \\
\hline Agropecuária - Ocupados (\%) & 0,1799 & $-0,0014$ & 0,0156 & 0,0948 & $-0,0009$ & 0,0063 & 0,2529 & $-0,0046$ & 0,0115 \\
\hline Extrativo Mineral - Ocupados (\%) & 0,0700 & $-0,0083$ & 0,0581 & 0,1976 & $-0,0379$ & 0,0914 & 0,3850 & $-0,0787$ & 0,1154 \\
\hline Transformação - Ocupados (\%) & 0,5713 & 0,0291 & 0,0289 & 0,6000 & 0,0222 & 0,0214 & 0,8829 & 0,0351 & 0,0160 \\
\hline Construção - Ocupados (\%) & 0,0589 & 0,0012 & 0,0214 & 0,0657 & 0,0004 & 0,0154 & 0,1018 & 0,0049 & 0,0202 \\
\hline SIUP - Ocupados $(\%)$ & 0,1450 & $-0,1149$ & 0,3559 & 0,0625 & $-0,0078$ & 0,0962 & 0,0955 & 0,0290 & 0,1268 \\
\hline Setor Público - Ocupados (\%) & 0,0719 & $-0,0001$ & 0,0081 & 0,0780 & $-0,0005$ & 0,0052 & 0,1018 & $-0,0014$ & 0,0060 \\
\hline Empresas - Até 49 Funcionários - Serviços financeiros (\%) & 0,0563 & 0,0008 & 0,0077 & 0,0557 & 0,0002 & 0,0046 & 0,0683 & 0,0008 & 0,0048 \\
\hline Empresas - Até 49 Funcionários (\%) & 0,0612 & 0,0030 & 0,0349 & 0,0898 & 0,0069 & 0,0341 & 0,1288 & 0,0107 & 0,0358 \\
\hline Empresas - Até 49 Funcionários - Empregados (\%) & 0,0828 & $-0,0003$ & 0,0041 & 0,0760 & 0,0003 & 0,0024 & 0,0725 & 0,0002 & 0,0020 \\
\hline
\end{tabular}


Tabela 12: Importância dos Canais de Transmissão - Resposta Máxima

\begin{tabular}{|c|c|c|c|c|c|c|c|c|c|}
\hline \multirow{2}{*}{ Covariadas } & \multicolumn{3}{|c|}{ Resposta Máxima } & \multicolumn{3}{|c|}{ I.C. $68 \%$} & \multicolumn{3}{|c|}{ I.C. $90 \%$} \\
\hline & PIP & Post Mean & Post SD & PIP & Post Mean & Post SD & PIP & Post Mean & Post SD \\
\hline Constante & 1,0000 & $-3,8361$ & - & 1,0000 & $-3,4708$ & - & 1,0000 & $-4,1349$ & - \\
\hline Anos de Estudo & 0,1479 & 0,1008 & 0,3402 & 0,0682 & $-0,0051$ & 0,0781 & 0,1012 & $-0,0170$ & 0,0951 \\
\hline Habitantes/Km² & 0,0642 & $-0,0001$ & 0,0012 & 0,1111 & 0,0002 & 0,0010 & 0,1255 & 0,0002 & 0,0007 \\
\hline Homicídios/100 mil Hab. & 0,0934 & $-0,0028$ & 0,0128 & 0,1320 & 0,0023 & 0,0078 & 0,0565 & 0,0000 & 0,0026 \\
\hline Indivíduos Abaixo da Linha de Pobreza (\%) & 0,1561 & $-0,0057$ & 0,0248 & 0,0862 & $-0,0005$ & 0,0090 & 0,0989 & 0,0016 & 0,0098 \\
\hline Renda Domiciliar Per Capita & 0,1089 & 0,0002 & 0,0010 & 0,0926 & 0,0000 & 0,0005 & 0,0987 & $-0,0001$ & 0,0005 \\
\hline Saldo de Operações de Crédito/PIB - PF & 0,0691 & $-0,0042$ & 0,0285 & 0,0613 & 0,0010 & 0,0103 & 0,0608 & 0,0005 & 0,0070 \\
\hline Saldo de Operações de Crédito/PIB - PJ & 0,0621 & 0,0009 & 0,0276 & 0,3351 & 0,0361 & 0,0585 & 0,0672 & 0,0017 & 0,0114 \\
\hline Agências/ 100 mil Hab. & 0,2346 & 0,0473 & 0,1022 & 0,2758 & 0,0409 & 0,0807 & 0,1536 & 0,0153 & 0,0484 \\
\hline Municípios Sem Agência e PAB (\%) & 0,1070 & $-0,0022$ & 0,0089 & 0,1098 & $-0,0012$ & 0,0047 & 0,1328 & $-0,0010$ & 0,0033 \\
\hline Serviços - Ocupados (\%) & 0,1399 & $-0,0160$ & 0,0569 & 0,1134 & $-0,0056$ & 0,0292 & 0,2302 & $-0,0053$ & 0,0404 \\
\hline Comércio - Ocupados (\%) & 0,2836 & 0,1779 & 0,3303 & 0,2039 & 0,0561 & 0,1325 & 0,1121 & 0,0158 & 0,0607 \\
\hline Agropecuária - Ocupados (\%) & 0,1102 & $-0,0081$ & 0,0460 & 0,0961 & $-0,0044$ & 0,0248 & 0,2469 & $-0,0162$ & 0,0406 \\
\hline Extrativo Mineral - Ocupados (\%) & 0,0535 & $-0,0014$ & 0,2517 & 0,0702 & $-0,0248$ & 0,1544 & 0,4377 & $-0,3127$ & 0,4106 \\
\hline Transformação - Ocupados (\%) & 0,2540 & 0,0419 & 0,0856 & 0,5667 & 0,0744 & 0,0745 & 0,8838 & 0,1158 & 0,0526 \\
\hline Construção - Ocupados (\%) & 0,1221 & 0,0680 & 0,2351 & 0,0566 & 0,0028 & 0,0529 & 0,0814 & 0,0102 & 0,0547 \\
\hline SIUP - Ocupados $(\%)$ & 0,0649 & $-0,1222$ & 0,9233 & 0,0546 & $-0,0099$ & 0,3421 & 0,0902 & 0,0818 & 0,3918 \\
\hline Setor Público - Ocupados (\%) & 0,0620 & $-0,0014$ & 0,0324 & 0,0664 & 0,0012 & 0,0176 & 0,0833 & $-0,0033$ & 0,0171 \\
\hline Empresas - Até 49 Funcionários - Serviços financeiros (\%) & 0,0534 & $-0,0024$ & 0,0382 & 0,0652 & 0,0033 & 0,0243 & 0,0653 & 0,0024 & 0,0156 \\
\hline Empresas - Até 49 Funcionários (\%) & 0,0606 & 0,0082 & 0,2066 & 0,0757 & 0,0192 & 0,1110 & 0,1286 & 0,0368 & 0,1234 \\
\hline Empresas - Até 49 Funcionários - Empregados (\%) & 0,1948 & 0,0160 & 0,0398 & 0,0603 & 0,0005 & 0,0071 & 0,0748 & 0,0005 & 0,0071 \\
\hline
\end{tabular}


Apesar dos sinais em linha com a teoria, a maioria das distribuições posterior apresenta desvio padrão bastante elevado se comparado com as médias, o que já é um indicativo do grau de incerteza existente, não só quanto à magnitude dos coeficientes, mas também quanto ao seu sinal. Uma forma mais fácil de analisar a posterior dos coeficientes é condicioná-la à inclusão da variável. Nas tabelas 13 e 14 estão os Intervalos de Credibilidade para as seis especificações utilizadas.

O único coeficiente cujo Intervalo de Credibilidade de 95\% não contém o zero para todas as seis especificações é a porcentagem da população ocupada empregada no setor da indústria de transformação. Dessa forma, é a covariada com menor grau de incerteza quanto ao seu sinal. Para os modelos construídos a partir da resposta total, outra covariada que se destaca é o número de agências por 100 habitantes.

Uma forma menos rígida de se analisar a posterior dos coeficientes é olhar para a probabilidade do mesmo apresentar valores positivos. O ideal é obter probabilidades muito altas ou muito baixas, indicando que existe pouca incerteza em relação ao seu sinal. A tabela 15 apresenta essas probabilidades construídas a partir da posterior condicional à inclusão.

Como já indicava o Intervalo de Credibilidade, a probabilidade do coeficiente da indústria de transformação, condicional à inclusão, ser positivo é maior do que 99\% para todas as especificações testadas. Dentre as outras variáveis do mix produtivo, o coeficiente do comércio também apresenta baixa incerteza em relação ao seu sinal.

Para as demais variáveis, são poucas as que apresentam evidência robusta de existir baixa incerteza em relação ao seu sinal, com destaque para o número de agências por 100 mil habitantes e para a quantidade de municípios sem agência ou posto de atendimento bancário. 
Tabela 13: Intervalo de Credibilidade Condicional à Inclusão - Resposta Total Acumulada 48 Meses

\begin{tabular}{lcccccc}
\hline & \multicolumn{2}{c}{ Total } & \multicolumn{2}{c}{ I.C. $68 \%$} & \multicolumn{2}{c}{ I.C. $90 \%$} \\
\cline { 2 - 7 } & $2.5 \%$ & $97.5 \%$ & $2.5 \%$ & $97.5 \%$ & $2.5 \%$ & $97.5 \%$ \\
\hline \hline Anos de Estudo & $-0,22$ & 0,30 & $-0,20$ & 0,07 & $-0,17$ & 0,08 \\
Habitantes/Km² & 0,00 & 0,00 & 0,00 & 0,00 & 0,00 & 0,00 \\
Homicídios/100 mil Hab. & $-0,01$ & 0,01 & 0,00 & 0,01 & $-0,01$ & 0.01 \\
Indivíduos Abaixo da Linha de Pobreza (\%) & $-0,02$ & 0,04 & $-0,01$ & 0,02 & $-0,01$ & 0,02 \\
Renda Domiciliar Per Capita & 0,00 & 0,00 & 0,00 & 0,00 & 0,00 & 0,00 \\
Saldo de Operações de Crédito/PIB - PF & $-0,03$ & 0,03 & $-0,01$ & 0,03 & $-0,01$ & 0,02 \\
Saldo de Operações de Crédito/PIB - PJ & $-0,02$ & 0,06 & 0,00 & 0,05 & $-0,01$ & 0,03 \\
Agências/ 100 mil Hab. & 0,00 & 0,15 & 0,01 & 0,12 & 0,00 & 0,07 \\
Municípios Sem Agência e PAB (\%) & $-0,01$ & 0,00 & $-0,01$ & 0,00 & $-0,01$ & 0,00 \\
Serviços - Ocupados (\%) & $-0,09$ & 0,00 & $-0,05$ & 0,02 & $-0,05$ & 0,02 \\
Comércio - Ocupados (\%) & 0,02 & 0,29 & 0,02 & 0,18 & $-0,04$ & 0,10 \\
Agropecuária - Ocupados (\%) & $-0,07$ & 0,04 & $-0,05$ & 0,02 & $-0,05$ & 0,00 \\
Extrativo Mineral - Ocupados (\%) & $-0,46$ & 0,26 & $-0,41$ & 0,03 & $-0,39$ & $-0,02$ \\
Transformação - Ocupados (\%) & 0,02 & 0,08 & 0,01 & 0,06 & 0,02 & 0,06 \\
Construção - Ocupados (\%) & $-0,14$ & 0,18 & $-0,11$ & 0,12 & $-0,03$ & 0,13 \\
SIUP - Ocupados (\%) & $-1,88$ & 0,28 & $-0,79$ & 0,56 & $-0,23$ & 0,85 \\
Setor Público - Ocupados (\%) & $-0,06$ & 0,05 & $-0,04$ & 0,03 & $-0,04$ & 0,01 \\
Empresas - Até 49 Funcionários - Serviços financeiros (\%) & $-0,04$ & 0,07 & $-0,03$ & 0,04 & $-0,02$ & 0,04 \\
Empresas - Até 49 Funcionários (\%) & $-0,20$ & 0,29 & $-0,09$ & 0,24 & $-0,03$ & 0,20 \\
Empresas - Até 49 Funcionários - Empregados (\%) & $-0,03$ & 0,02 & $-0,01$ & 0,02 & $-0,01$ & 0,01 \\
\hline
\end{tabular}

Tabela 14: Intervalo de Credibilidade Condicional à Inclusão - Resposta Máxima Acumulada 48 Meses

\begin{tabular}{lcccccc}
\hline & \multicolumn{2}{c}{ Total } & \multicolumn{2}{c}{ I.C. $68 \%$} & \multicolumn{2}{c}{ I.C. $90 \%$} \\
\cline { 2 - 7 } & $2.5 \%$ & $97.5 \%$ & $2.5 \%$ & $97.5 \%$ & $2.5 \%$ & $97.5 \%$ \\
\hline \hline Anos de Estudo & $-0,33$ & 1,88 & $-0,61$ & 0,36 & $-0,62$ & 0,22 \\
Habitantes/Km² & $-0,01$ & 0,01 & 0,00 & 0,01 & 0,00 & 0,00 \\
Homicídios/100 mil Hab. & $-0,09$ & 0,03 & $-0,01$ & 0,04 & $-0,02$ & 0,02 \\
Indivíduos Abaixo da Linha de Pobreza (\%) & $-0,10$ & 0,05 & $-0,05$ & 0,06 & $-0,02$ & 0,07 \\
Renda Domiciliar Per Capita & 0,00 & 0,01 & 0,00 & 0,00 & 0,00 & 0,00 \\
Saldo de Operações de Crédito/PIB - PF & $-0,24$ & 0,11 & $-0,05$ & 0,09 & $-0,04$ & 0,06 \\
Saldo de Operações de Crédito/PIB - PJ & $-0,18$ & 0,23 & 0,01 & 0,20 & $-0,04$ & 0,10 \\
Agências/ 100 mil Hab. & $-0,01$ & 0,41 & 0,00 & 0,34 & $-0,02$ & 0,27 \\
Municípios Sem Agência e PAB (\%) & $-0,06$ & 0,01 & $-0,03$ & 0,01 & $-0,02$ & 0,00 \\
Serviços - Ocupados (\%) & $-0,31$ & 0,07 & $-0,21$ & 0,05 & $-0,17$ & 0,09 \\
Comércio - Ocupados (\%) & 0,01 & 1,25 & $-0,03$ & 0,58 & $-0,09$ & 0,36 \\
Agropecuária - Ocupados (\%) & $-0,30$ & 0,12 & $-0,18$ & 0,05 & $-0,18$ & 0,00 \\
Extrativo Mineral - Ocupados (\%) & $-2,00$ & 2,13 & $-1,24$ & 0,58 & $-1,32$ & $-0,10$ \\
Transformação - Ocupados (\%) & 0,00 & 0,33 & 0,03 & 0,22 & 0,07 & 0,19 \\
Construção - Ocupados (\%) & $-0,27$ & 1,37 & $-0,35$ & 0,47 & $-0,14$ & 0,41 \\
SIUP - Ocupados (\%) & $-7,96$ & 3,97 & $-2,86$ & 2,54 & $-0,87$ & 2,72 \\
Setor Público - Ocupados (\%) & $-0,26$ & 0,22 & $-0,11$ & 0,13 & $-0,12$ & 0,05 \\
Empresas - Até 49 Funcionários - Serviços financeiros (\%) & $-0,37$ & 0,26 & $-0,12$ & 0,20 & $-0,06$ & 0,13 \\
Empresas - Até 49 Funcionários (\%) & $-1,58$ & 1,59 & $-0,34$ & 0,85 & $-0,10$ & 0,70 \\
Empresas - Até 49 Funcionários - Empregados (\%) & $-0,01$ & 0,18 & $-0,04$ & 0,06 & $-0,04$ & 0,05 \\
\hline
\end{tabular}


Tabela 15: Probabilidade de Coeficiente Positivo - Condicional à Inclusão

\begin{tabular}{lcccccc}
\hline & \multicolumn{3}{c}{ Resposta Acum. 48 meses } & \multicolumn{3}{c}{ Resposta Acum. Máxima } \\
\cline { 2 - 6 } & Total & I.C. 68\% & I.C. 90\% & Total & I.C. 68\% & I.C. 90\% \\
\hline \hline Anos de Estudo & $62,68 \%$ & $15,02 \%$ & $36,83 \%$ & $96,17 \%$ & $45,56 \%$ & $27,18 \%$ \\
Habitantes/Km ${ }^{2}$ & $98,31 \%$ & $94,37 \%$ & $98,52 \%$ & $36,33 \%$ & $94,34 \%$ & $97,60 \%$ \\
Homicídios/100 mil Hab. & $69,83 \%$ & $85,28 \%$ & $43,12 \%$ & $6,32 \%$ & $95,21 \%$ & $53,06 \%$ \\
Indivíduos Abaixo da Linha de Pobreza (\%) & $58,69 \%$ & $84,58 \%$ & $54,36 \%$ & $8,15 \%$ & $26,55 \%$ & $65,37 \%$ \\
Renda Domiciliar Per Capita & $58,22 \%$ & $14,67 \%$ & $49,21 \%$ & $83,66 \%$ & $53,91 \%$ & $35,34 \%$ \\
Saldo de Operações de Créditito/PIB - PF & $36,85 \%$ & $88,61 \%$ & $78,15 \%$ & $15,51 \%$ & $87,56 \%$ & $77,74 \%$ \\
Saldo de Operações de Crédito/PIB - PJ & $86,17 \%$ & $100,00 \%$ & $99,02 \%$ & $47,85 \%$ & $100,00 \%$ & $95,45 \%$ \\
Agências/ 100 mil Hab. & $99,02 \%$ & $99,94 \%$ & $99,10 \%$ & $99,54 \%$ & $99,98 \%$ & $98,39 \%$ \\
Municípios Sem Agência e PAB (\%) & $1,67 \%$ & $1,49 \%$ & $0,84 \%$ & $4,30 \%$ & $2,70 \%$ & $0,27 \%$ \\
Serviços - Ocupados (\%) & $3,58 \%$ & $33,65 \%$ & $64,85 \%$ & $11,07 \%$ & $26,49 \%$ & $61,74 \%$ \\
Comércio - Ocupados (\%) & $100,00 \%$ & $99,92 \%$ & $93,16 \%$ & $100,00 \%$ & $99,99 \%$ & $97,51 \%$ \\
Agropecuária - Ocupados (\%) & $49,26 \%$ & $25,27 \%$ & $2,37 \%$ & $20,74 \%$ & $17,98 \%$ & $2,09 \%$ \\
Extrativo Mineral - Ocupados (\%) & $17,25 \%$ & $0,00 \%$ & $0,00 \%$ & $50,85 \%$ & $0,05 \%$ & $0,00 \%$ \\
Transformação - Ocupados (\%) & $99,44 \%$ & $99,96 \%$ & $99,92 \%$ & $99,12 \%$ & $99,97 \%$ & $99,87 \%$ \\
Construção - Ocupados (\%) & $74,07 \%$ & $56,64 \%$ & $97,25 \%$ & $99,96 \%$ & $70,01 \%$ & $94,26 \%$ \\
SIUP - Ocupados (\%) & $2,50 \%$ & $26,64 \%$ & $97,07 \%$ & $13,05 \%$ & $38,87 \%$ & $95,19 \%$ \\
Setor Público - Ocupados (\%) & $46,18 \%$ & $33,56 \%$ & $5,94 \%$ & $40,66 \%$ & $68,21 \%$ & $4,10 \%$ \\
Empresas - Até 49 Funcionários - Serviços financeiros (\%) & $89,98 \%$ & $70,67 \%$ & $98,90 \%$ & $23,39 \%$ & $85,81 \%$ & $99,17 \%$ \\
Empresas - Até 49 Funcionários (\%) & $79,54 \%$ & $93,55 \%$ & $99,52 \%$ & $64,14 \%$ & $95,50 \%$ & $99,68 \%$ \\
Empresas - Até 49 Funcionários - Empregados (\%) & $50,74 \%$ & $73,52 \%$ & $75,09 \%$ & $99,79 \%$ & $79,31 \%$ & $61,55 \%$ \\
\hline
\end{tabular}




\section{CONCLUSÃO}

O estudo das respostas estaduais a um choque de política monetária e a compreensão dos determinantes dessa heterogeneidade vêm sendo tratados de forma separada na literatura nacional. Com a recente exceção de Rocha et at (2011), parte majoritária da literatura foca apenas na estimação das respostas estaduais. O objetivo deste trabalho foi tratar os dois temas dentro de um mesmo arcabouço metodológico, contribuindo assim para a compreensão do comportamento das Unidades Federativas frente a um choque na taxa de juros. Para tanto, seguiu-se Francis et al (2012), que aplicam técnicas Bayesianas ao procedimento de duas etapas proposto por Carlino e Defina (1999).

Em primeiro lugar, utilizou-se um VAR Bayesiano para estimar o impacto regional de uma inovação exógena na política do Banco Central. Os resultados encontrados apontam para uma forte heterogeneidade nas respostas das Unidades Federativas brasileiras. São Paulo, Rio Grande do Sul e Paraná são, respectivamente, os Estados mais sensíveis. Analisando a dispersão geográfica das respostas estimadas, é possível concluir que as regiões Sul e Sudeste apresentam as maiores contrações em resposta a um choque positivo na taxa de juros. No outro extremo, destaca-se a região Norte como um todo, com exceção ao Estado do Amazonas.

Os resultados mostram ainda que as funções impulso resposta dos Estados mais sensíveis apresentam menor grau de incerteza, tanto em seu formato, como em seu sinal. Já para a região Norte, além de alguns Estados da região Nordeste, a distribuição posterior das funções impulso resposta é bastante dispersas entre valores positivos e negativos do espaço paramétrico.

Dessa forma, as evidências encontradas estão em linha com a literatura nacional ao indicar que as Unidades Federativas brasileiras respondem de forma assimétrica a uma inovação monetária. Contudo, o padrão encontrado assemelha-se mais ao obtido por Araújo (2004) que, ao comparar as respostas dos Estados da região Sul com as da região Nordeste, conclui pela maior sensibilidade dos Estados sulistas. Vasconcelos e Fonseca (2002) também apontam para a maior sensibilidade de São Paulo e Rio Grande do Sul.

A partir das funções impulso resposta, construíram-se medidas de sensibilidade para as 27 Unidades Federativas brasileiras. Tais medidas foram regredidas contra variáveis proxy 
para os canais de transmissão de política monetária. Dúvidas em relação a quais variáveis explicativas incluir no modelo foram tratadas através do Bayesian Model Averaging, metodologia que permite formalizar a incerteza em relação não só ao espaço paramétrico, como também ao espaço de modelos.

Encontrou-se evidência de um alto grau de incerteza em relação a quais variáveis deveriam ser incluídas na estimação, uma vez que todas apresentaram probabilidades de inclusão relativamente baixas. Entretanto, a porcentagem da população ocupada empregada na indústria de transformação destacou-se em relação às demais variáveis, para todas as especificações testadas. Ao considerar apenas os pontos da função impulso resposta nos quais havia baixo grau de incerteza em relação ao seu sinal, a probabilidade de inclusão dessa variável elevou-se, chegando a quase $90 \%$. Os resultados encontrados apontam para a forte relevância do canal de juros na determinação da heterogeneidade de resposta a um choque de política monetária.

Não foram encontradas evidências da presença do canal de crédito no nível estadual, uma vez que as variáveis como porcentagem de firmas e bancos pequenos apresentaram probabilidades de inclusão quase sempre abaixo de $10 \%$. O grau de penetração do sistema financeiro mostrou-se importante para a determinação das diferentes respostas regionais, apresentando PIP acima da média para algumas especificações testadas. Por fim, variáveis relacionadas às características socioeconômicas também não se mostraram relevantes para a determinação das respostas estaduais.

Em linhas gerias, os resultados obtidos são diferentes dos encontrados em Rocha et at (2011). Para os autores, a indústria de transformação não se mostrou significativa na determinação das assimetrias regionais. Já variáveis relacionadas ao tamanho das firmas e bancos mostraram-se significantes. Apesar das divergências em relação ao principais resultados encontrados neste trabalho, Rocha et at (2011) também encontram evidências da importância do grau de penetração do sistema financeiro.

Apesar de a política monetária ser formulada com base no comportamento das variáveis macroeconômicas agregadas e de forma horizontal para todas as Unidades Federativas, é importante que seus efeitos regionais sejam analisados e compreendidos. Diferentes resultados podem levar a prescrições de políticas completamente opostas. As evidências 
reportadas acima indicam que uma maior homogeneidade regional dos choques monetários passa por uma maior presença da indústria de transformação nas economias estaduais, assim como por uma maior penetração do sistema bancário. É interessante notar que, por encontrar respostas diferentes das obtidas neste estudo, Rocha (2007) apresenta recomendações distintas.

Assim, a diversidade de conclusões presentes na literatura nacional aponta para a necessidade de se continuar aplicando diferentes metodologias ao tema. Juntar o arcabouço de econometria regional [BERTANHA; HADDAD, 2008] com a metodologia Bayesiana pode ser uma estratégia interessante para pesquisas futuras. Caminhar para desagregações mais finas, como em Francis et al (2012), também constitui uma agenda pouco explorada para o Brasil. 


\section{REFERÊNCIAS}

ARAÚJO, Eurilton. Medindo o impacto regional da política monetária brasileira: uma comparação entre as regiões Nordeste e Sul. Revista Econômica do Nordeste, v. 35, n. 3, p. 356-393, 2004.

ARNOLD, Ivo JM; VRUGT, Evert B. Regional effects of monetary policy in the Netherlands. International Journal of Business and Economics, v. 1, n. 2, p. 123-134, 2002.

ARQUETE, Lílian Carla dos Reis; JÚNIOR, Frederico Gonzaga Jayme. Política monetária, preços e produto no Brasil (1994-2002): uma aplicação de vetores autoregressivos. ANPEC-Associação Nacional dos Centros de Pós-graduação em Economia [Brazilian Association of Graduate Programs in Economics], 2003.

BALL, Laurence. Time-consistent policy and persistent changes in inflation. Journal of Monetary Economics, v. 36, n. 2, p. 329-350, 1995.

BAŃBURA, Marta; GIANNONE, Domenico; REICHLIN, Lucrezia. Large Bayesian vector auto regressions. Journal of Applied Econometrics, v. 25, n. 1, p. 71-92, 2010.

BARTH III, Marvin J.; RAMEY, Valerie A. The cost channel of monetary transmission. In: NBER Macroeconomics Annual 2001, Volume 16. MIT Press, p. 199-256, 2002.

BEKKER, Paul A.; POLLOCK, D. S. G. Identification of linear stochastic models with covariance restrictions. Journal of Econometrics, v. 31, n. 2, p. 179-208, 1986.

BERNANKE, Ben S.; GERTLER, Mark. Inside the black box: the credit channel of monetary policy transmission. National bureau of economic research, 1995.

BERNANKE, Ben S.; MIHOV, Ilian. Measuring monetary policy. National Bureau of Economic Research, 1998. 
BERTANHA, Marinho; HADDAD, Eduardo Amaral. Efeitos regionais da política monetária no Brasil: impactos e transbordamentos espaciais. Revista Brasileira de Economia, v. 62, n. 1, p. 3-29, 2008.

BLAKE, Andrew P.; MUMTAZ, Haroon. Applied Bayesian econometrics for central bankers. Technical Books, 2012.

BRAVO, Héctor Felipe. Heterogeneidad de la trasmisión monetaria: efectos sectoriales y regionales. Banco Central de Chile, 2003.

CANOVA, Fabio. Methods for applied macroeconomic research. Princeton University Press, 2007.

CARLINO, Gerald; DEFINA, Robert. The differential regional effects of monetary policy: Evidence from the US states. Journal of Regional Science, v. 39, n. 2, p. 339358, 1999.

CHARI, Varadarajan V.; CHRISTIANO, Lawrence J.; EICHENBAUM, Martin. Expectation traps and discretion. Journal of economic theory, v. 81, n. 2, p. 462-492, 1998.

CHRISTIANO, Lawrence J.; EICHENBAUM, Martin; EVANS, Charles L. Monetary policy shocks: What have we learned and to what end?. Handbook of macroeconomics, v. 1, p. 65-148, 1999.

CÉSPEDES, Brisne; LIMA, Elcyon; MAKA, Alexis. Monetary policy, inflation and the level of economic activity in Brazil after the Real Plan: stylized facts from SVAR models. Revista Brasileira de Economia, v. 62, n. 2, p. 123-160, 2008.

DE MOL, Christine; GIANNONE, Domenico; REICHLIN, Lucrezia. Forecasting using a large number of predictors: Is Bayesian shrinkage a valid alternative to principal components?. Journal of Econometrics, v. 146, n. 2, p. 318-328, 2008.

DEL NEGRO, Marco; SCHORFHEIDE, Frank. Bayesian macroeconometrics. The Oxford handbook of Bayesian econometrics, p. 293-389, 2011. 
DI GIACINTO, Valter. Differential regional effects of monetary policy: a geographical SVAR approach. International Regional Science Review, v. 26, n. 3, p. 313-341, 2003.

DOAN, Thomas; LITTERMAN, Robert; SIMS, Christopher. Forecasting and conditional projection using realistic prior distributions. Econometric reviews, v. 3, n. 1, p. 1-100, 1984.

DRAPER, David. Assessment and propagation of model uncertainty. Journal of the Royal Statistical Society. Series B (Methodological), p. 45-97, 1995.

FERNANDEZ, Carmen; LEY, Eduardo; STEEL, Mark FJ. Benchmark priors for Bayesian model averaging. Journal of Econometrics, v. 100, n. 2, p. 381-427, 2001a.

FERNANDEZ, Carmen; LEY, Eduardo; STEEL, Mark FJ. Model uncertainty in cross-country growth regressions. Journal of applied Econometrics, v. 16, n. 5, p. 563-576, 2001b.

FORNI, Mario; HALLIN, Marc; LIPPI, Marco; REICHLIN, Lucrezia. Reference cycles: the NBER methodology revisited. Centre for Economic Policy Research, 2000 .

FRANCIS, Neville et al. The Local Effects of Monetary Policy. The BE Journal of Macroeconomics, v. 12, n. 2, p. 1-38, 2012.

HODGES, James S. Uncertainty, policy analysis and statistics. Statistical science, p. 259-275, 1987.

KOOP, Gary. Bayesian Econometrics. John Wiley. 2003.

KOOP, Gary; KOROBILIS, Dimitris. Bayesian multivariate time series methods for empirical macroeconomics. Now Publishers Inc, 2010. 
LEEPER, Eric M.; SIMS, Christopher A; ZHA, Tao. What does monetary policy do?. Brookings papers on economic activity, p. 1-78, 1996.

LITTERMAN, Robert B. Forecasting with Bayesian vector autoregressions-five years of experience. Journal of Business \& Economic Statistics, v. 4, n. 1, p. 25-38, 1986.

DE LUCIO, Julio; IZQUIERDO, Mario. Local responses to a global monetary policy: The regional structure of financial systems. Documento de trabajo, v. 99, p. $14,1999$.

MADIGAN, David; YORK, Jeremy; ALLARD, Denis. Bayesian graphical models for discrete data. International Statistical Review/Revue Internationale de Statistique, p. 215-232, 1995.

MILLER, Randall J. The regional impact of monetary policy in the United States. Lexington, MA: Lexington Books, 1978.

MINELLA, André. Monetary policy and inflation in Brazil (1975-2000): a VAR estimation. Revista Brasileira de Economia, v. 57, n. 3, p. 605-635, 2003.

MISHKIN, Frederic S. The channels of monetary transmission: lessons for monetary policy. National Bureau of Economic Research, 1996.

OWYANG, Michael T.; WALL, Howard J. Regional disparities in the transmission of monetary policy. Federal Reserve Bank of St. Louis, 2003.

POIRIER, Dale J. Intermediate statistics and econometrics: A comparative approach. MIT Press, 1995.

ROCHA, Bruno de Paula. Ensaios sobre economia bancária e política monetária no Brasil em uma abordagem regionalizada. 2007. Tese (Doutorado em Teoria Econômica) - Faculdade de Economia, Administração e Contabilidade, Universidade de São Paulo, São Paulo, 2007. 
ROCHA, Roberta de Moraes; SILVA, Marcelo Eduardo Alves da; GOMES, Sónia Maria Fonseca Pereira Oliveira. Por que os estados brasileiros têm reações assimétricas a choques na política monetária?. Revista Brasileira de Economia, v. 65, n. 4, p. 413-441, 2011.

SALA, Luca. Monetary transmission in the euro area: a factor model approach. October, manuscript,(www. dynfactors. org), 2001.

SIMS, Christopher A. Macroeconomics and reality. Econometrica: Journal of the Econometric Society, p. 1-48, 1980.

SIMS, Christopher A. Interpreting the macroeconomic time series facts: The effects of monetary policy. European Economic Review, v. 36, n. 5, p. 975-1000, 1992.

SIMS, Christopher A. A nine-variable probabilistic macroeconomic forecasting model. In: Business Cycles, Indicators and Forecasting. University of Chicago Press, 1993. p. 179-212.

SIMS, Christopher A.; ZHA, Tao. Error bands for impulse responses. Econometrica, v. 67, n. 5 , p. 1113-1155, 1999.

SIMS, Christopher A.; ZHA, Tao. Bayesian methods for dynamic multivariate models. International Economic Review, p. 949-968, 1998.

VASCONCELOS, Marcos R., DA FONSECA, Marcos W. Política monetária no Brasil: mecanismos de transmissão e impactos diferenciados nas regiões e estados da federação. Anais da ANPEC, 2002.

WAGGONER, Daniel F.; ZHA, Tao. A Gibbs sampler for structural vector autoregressions. Journal of Economic Dynamics and Control, v. 28, n. 2, p. 349-366, 2003 . 
ZELLNER, Arnold. On assessing prior distributions and Bayesian regression analysis with g-prior distributions. Bayesian inference and decision techniques: Essays in Honor of Bruno De Finetti, v. 6, p. 233-243, 1986.

ZHA, Tao. Block recursion and structural vector autoregressions. Journal of Econometrics, v. 90, n. 2, p. 291-316, 1999. 